Kinctic Behavior of Solid Particles in Fluidized Beds

Annual Report

H.O. Kono

C-C. Huang

October 1987

Work Performed Under Contract No.: DE-AC21-86MC23249

For

U.S. Department of Energy

Office of Fossil Energy

Morgantown Energy Technology Center

Morgantown, West Virginia

By

West Virginia University

Department of Chemical Engineering

Morgantown, West Virginia

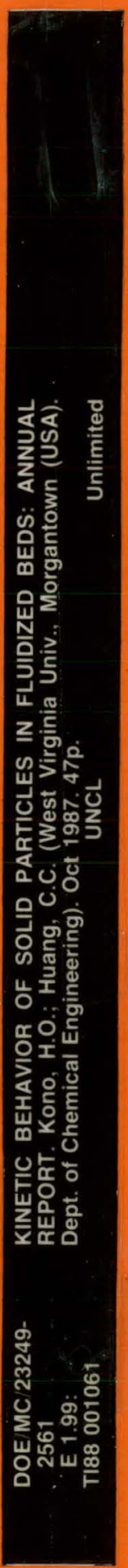




\section{DISCLAIMER}

This report was prepared as an account of work sponsored by an agency of the United States Government. Neither the United States Government nor any agency Thereof, nor any of their employees, makes any warranty, express or implied, or assumes any legal liability or responsibility for the accuracy, completeness, or usefulness of any information, apparatus, product, or process disclosed, or represents that its use would not infringe privately owned rights. Reference herein to any specific commercial product, process, or service by trade name, trademark, manufacturer, or otherwise does not necessarily constitute or imply its endorsement, recommendation, or favoring by the United States Government or any agency thereof. The views and opinions of authors expressed herein do not necessarily state or reflect those of the United States Government or any agency thereof. 


\section{DISCLAIMER}

Portions of this document may be illegible in electronic image products. Images are produced from the best available original document. 


\section{DISCLAIMER}

This report was prepared as an account of work sponsored by an agency of the United States Government. Neither the United States Government nor any agency thereof, nor any of their employees, makes any warranty, express or implied, or assumes any legal liability or responsibility for the accuracy, completeness, or usefulness of any information, apparatus, product, or process disclosed, or represents that its use would not infringe privately owned rights. Reference herein to any specific commercial product, process, or service by trade name, trademark, manufacturer, or otherwise does not necessarily constitute or imply its endorsement, recommendation, or favoring by the United States Government or any agency thereof. The views and opinions of authors expressed herein do not necessarily state or reflect those of the United States Government or any agency thereof.

This report has been reproduced directly from the best available copy.

Available from the National Technical Information Service, U. S. Department of Commerce, Springfield, Virginia 22161.

Price: Printed Copy A03

Microfiche A01

Codes are used for pricing all publications. The code is determined by the number of pages in the publication. Information pertaining to the pricing codes can be found in the current issues of the following publications, which are generally available in most libraries: Energy Reseurch Alstructs (ERA); Government Reports Announcements and Index (GRA and I); Sctentific and Technicul Abstruct Reports (STAR); and publication NTIS-PR-360 available from NTIS at the above address. 


\title{
Kinetic Behavior of Solid Particles in Fluidized Beds
}

\author{
Annual Report
}

\author{
H.O. Kono \\ C-C. Huang
}

Work Performed Linder Contract No.: DE-AC21-86MC23249

For

U.S. Department of Energy

Office of Fossil Energy

Morgantow'n Energy Technology Center

P.O. Box 880

Morgantow'n, W'est Virginia 26507-0880

By

West Virginia University

Department of Chemical Engineering

P.O. Box 6101

Morgantown, West Virginia 26508-6101

October 1987 


\section{THIS PAGE}

WAS INTENTIONALLY

LEFT BLANK 


\begin{abstract}
This report summarizes technical accomplishments for the first year in a 3-year contract project for the Morgantown Energy Technology Center (METC) of the U.S. Department of Energy (DOE) under contract number DE-AC21-86MC23249. The objectives of the project are (1) to develop experimental techniques for measuring the forces of fluidized particles, and (2) to predict solid particle performance in fluidized beds using data analyais and mathematical modeling. During the first year, the fracture-sensitive tracer-particle method was developed and applied to investigate the effects of fluidized particle size, superficial gas velocity, bed height, bed diameter, and bed configuration on the kinetic behavior of solid particles in fluidized beds. Quantitative data and comprehensive information were obtained. A piezoresistive strain-gauge sensor and a PC data-acquisition system were also developed; these are being used to messure the force distribution in fluidized beds. The pressure fluctuation method will also be investigated in the near future.
\end{abstract}


EXECUTIVE SUMMARY . . . . . . . . . . . . . . . . . . . 1

1.0 INTRODUCTION . . . . . . . . . . . . . . . . . . 3

1.1 Purpose ....................... 3

1.2 Background . . . . . . . . . . . . . . . . 3

2.0 METHODOLOGY . . . . . . . . . . . . . . . . . . . 5

2.1 The Fracture-Sensitive Tracer-Particle Method . . . . . . 5

2.1.1 Preparation and Galibrotion

of Fracture-Sensitive Tracer Particles . . . . . . . 5

2.1.2 Correlation Between the Durable Compressive

Force and the Durable Impact Energy of

Fracture-Sensitive Tracer Particles . . . . . . 7

2.1.3 Experimental Procedure . . . . . . . . . . . . . 11

2.1.4 The Effect of Fluidizing-Air Humidity on the Force Measurement . . . . . . . . . . . . 14

2.1.5 Video Observation of the Destruction of Fracture-Sensitive Tracer Particles in

a Two-Dimensional Fluidized Bed . . . . . . . . 14

2.2 Piezoresistive Strain-Gauge Method . . . . . . . . . 17

2.2.1 General Remarks . . . . . . . . . . . . . . . . 17

2.2.2 Design and Calibration of the Piezotron Sensor . . . 17

2.2.3 Development of Data Acquisition System . . . . . 20

3.0 RESULTS AND DISCUSSION . . . . . . . . . . . . . . 23

4.0 OONCLUSION . . . . . . . . . . . . . . . . . . . . . . . . . .

5.0 NOMENCLATURE . . . . . . . . . . . . . . . . . . . 39

6.0 REFERENCES .........................40 


\section{LIST OF FIGURES}

Experimental Verification of Rumpf's Equation . . . . . . 6

Experimental Verification of Hiramatsu's Equation . . . . . 8

3 Experimental Relationship Between Dymamic Impact

Energy and Durable Static Compressive Force . . . . . . . . 10

Schematic Diagram of the Experimental Apparatus . . . . . i2

Estimation of the Minimum Value of Dimensionless

Gas Velocity at Which Fracture-Sensitive

Tracer Particles of Known Strength Were Totally

Destroyed . . . . . . . . . . . . . . . . . 13

6 The Effect of the Relative Humidity of Fluidizing Air

on the Survival Ratio of Tracer Particles . . . . . . . . . 15

7 The Effect of the Relative Humidity of Fluidizing Air on the Prevailing Kinetic Forces in a Fluidized Bed . . . 16

The Structure of the Piezotron Sensor . . . . . . . . . . . 18

Schematic Diagram of the Piezotron Sensor Apparatus . . . . 19

Force Signals Obtained From the Piezotron Sensor . . . . : 21

11 The Force Distribution of Solid Particles in a

Fluidized Bed . . . . . . . . . . . . . . . . . 22

12 The Effects of Particle Size, Bed Aspect Ratio, and Gas

Velocity on the Prevailing Kinetic Forces in a $0.108 \mathrm{~m} \mathrm{I.D.}$

Fluidized Bed.. . . . . . . . . . . . . . . . . . 24

13 The Effects of Particle Szie, Bed Aspect Ratio, and Gas

Velucity uis the Prevailing Kinetic Forces in a 0.203 m I.D.

Fluidized Bed . . . . . . . . . . . . . . . . . 25

14 The Effects of Particle Size, Bed Aspect Ratio, and Gas

Velocity on the Prevailing Kinetic Forces in a $0.292 \mathrm{~m} \mathrm{I.D.}$

Fluidized Bed.. . . . . . . . . . . . . . . . . . 26

15 The Bffect of Bed Diameter on the Prevailing Binetic

Forces in Fluidized Beds at a Constant Bed Aspect Ratio . . 27

16 The Bffect of Bed Diameter on the Prevailing Kinetic

Forces in Fluidized Beds at $a$ Bed Height of $0.203 \mathrm{~m}$. . . 28

17 The Effect of Bed Dimeter on the Prevailing Kinetic

Forces in Fluidized Beds at a Bed Height of $0.292 \mathrm{~m}$. . . . 29 


\section{LIST OF FIGURES}

(continued)

Figure

$\underline{\text { Page }}$

18 The Relationship Between the Pressure Drop Across Gas Distributors and Superficial Gas Velocity . . . . . . 30

19 The Effect of the Gas Distributor on Prevailing Kinetic Forces in a Fluidized Bed at Low Gas Velocities . . . . . . 31

The Effect of the Gas Distributor on Prevailing Kinetic Forces in a Fluidized Bed at High Gas Velocities . . . . 32

21 The Effects of Particle Size, Gas Velocity and Bed Height on the Prevailing Kinetic Forces in a $0.108 \mathrm{mI}$.D. Spoutcd Fluidizod bod at $X-0.6$. . . . . . . . . . . . 33

22 The Effect of Volumetric Flow Ratio on the Prevailing Kinetic Forces in a $0.108 \mathrm{~m}$ I.D. Spouted Fluidized Bed . . 35 Kinetic Forces of Solid Particles in a $0.108 \mathrm{~m}$ Square Fluidized Bed.................... . 36

24 Comparison of Kinetic Forces of Solid Particles in Various Fluidized Beds .. . . . . . . . . . . . 37

\section{LIST OF. TABLES}

Physical and Mechanical Properties of FractureSensitive Tracer Particles... . . . . . . . . . 9 


\section{EXECUTIVE SUMMARY}

Experimental techniques have been developed for measuring the forces of solid particles in fluidized beds. The fracture-sensitive tracer-particle method (using granules with a known mechanical strength), piezoresistive strain-gauge method, and pressure fluctuation method are being employed to evaluate the stochastic behavior of solid particles and the force distribution in fluidized beds. Generally speaking, erosion and attrition in fluidized beds consist of two factors: i.e., stochastic forces prevailing in fluidized beds, and the physical properties of the fluidized particles. To have an intrinsic understanding of this behavior; the effect of the two factors should be elucidated separately. The results of this study will assist the design and operation of fluidized-bed combustors and gasifiers that can minimize erosion and attrition.

The fracture-sensitive tracer-particle method was developed and experimentally verified. Tracer particles of known mechanical strength, quantified by Rumf and Hiramasu's equations, were employed to evaluate the representative forces that cause erosion and attrition in fluidized beds. Several fluidized beds including the two-dimensional bed, square bed, circular bed, and spouted fluidized bed were constructed for the force measurement experiments.

The forces of fluidized particles could be affected by the humidity of the fluidizing air if the water vapor in the air condensed on the fluidized particles. A relative humidity of 50 percent at $200 \mathrm{C}$ and 1 atm was experimentally chosen as the fluidizing air condition in this study. The forces of fluidized particles were found to increase with an increase in particle size, superficial gas velocity, and bed height.

The effect of bed diameter on the forces of fluidized particles was found to be not as significant as that of bed height. The bed diameter effect on these was found to be negligible when the inside diameter (I.D.) was larger than $0.203 \mathrm{~m}$.

The presence of large bubbles and unstable fluidization indicates slugging fluidization. Although most fluidized-bed combustion and gasification units are claimed to be at the bubbling fluidization condition, it is more likely to be a combination of bubbling and slugging, depending on the operating conditions and the size of the fluidized beds. Severe bubble coalescence that forms large bubbles and causes unstable fluidization was generally observed in the coarse-particle fluidized bed, especially for small bed diameters. For relatively large bed diameters, the coarse-particle fluidized bed may perform close to a bubbling bed at low gas velocities. Therefore, the term "slugging" is a measure of the degree of unstable fluidization, and this degree depends on how the gas bubbles grow in the bed. At a lower level of slugging, fluidization can be considered to be bubbling, and the forces of fluidized particles are smaller. 
Bed configuration proved to have a significant influence on the forces of fluidized particles. At the same superficial gas velocity and bed height, experiments showed that a circular bed tends more to slugging and the fluidized particles have a higher force than in a square fluidized bed. The degree of slugging in a two-dimensional fluidized bed is lower than that in a square fluidized bed; and the solid particles in a two-dimensional fluidized bed have a lower force than those in a square fluidized bed. Bed configuration may influence the forces of fluidized particles because of the wall effect; however, more investigation is necessary to reach a final conclusion. As for the spouted fluidized bed, the particles have a higher force than those in the same gize circular fluidized bed because of the existence of an air jet.

The effect that the volumetric flow ratio of fluidizing air through the jet in a spnuted fluidized hed has on the forces of solid particles was also investigated. The fluidized particles had sreater force at a volumetric flow ratio of 0.5 . This indicates that both the jet and the conical perforated gas distributor are responsible for developing the forces of solid particles in a spouted fluidized bed.

The effect of the gas distributor on the forces of fluidized particles depends on the superficial gas velocity. At lower gas velocities, different types of gas distributors do not affect the forces of fluidized particles. However, a gas distributor with a higher pressure drop may cause the fluidized particles to have greater force when the gas velocity is larger than $1.5 \mathrm{~m} / \mathrm{s}$.

The destruction of fracture-sensitive tracer particles in a two-dimensional fluidized bed was observed by video. The tracer particles seemed to be destroyed as they moved into the bubblewake arey. A suecalled "ohedding" phenomenon existing in tho wake may create transient fluctuations and locally high forces. In. addition, a piezoresistive strain-gauge sensor, PC data-acquisition software, and custom programs were developed. These are being used to gather data and to calculate the force distribution in fluidized beds. 


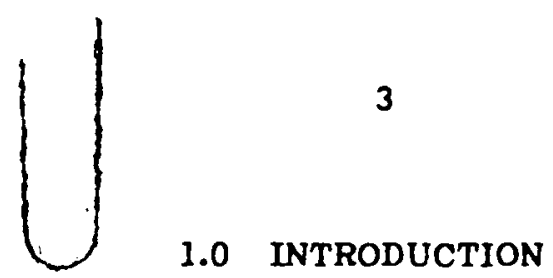

\subsection{Purpose}

The force of solid particles determines the fundamental characteristics of a fluidized bed. This force also causes attrition of fluidized particles, erosion of vessels and boiler tubes, and vibration of fluidization systems. Therefore, a study of the force that fluidized particles have is of vital importance for designing coarse-particle fluidized-bed reactors such as fluidized bed combustors.

Experimental data on the attrition of fluidized particles have been published by Kono (1981) and Vaux and Fellers (1981). However, attrition depends not only on the prevailing forces of solid particles, but also on the physical properties of the particles themselves. To have an intrinsic understanding on this behavior, the effect of these two factors should be investigated separately.

The objectives of this project are to develop experimental techniques to measure the forces of fluidized particles and to predict the performance of solid particles in fluidized beds using data analysis and mathematical modeling. This study will assist in designing and operating fluidized-bed combustors and gasifiers that can minimize erosion and attrition.

\subsection{Background}

Experimental techniques have been presented for investigating particle dynamics in fluidized beds (Marsheck and Gomezplata 1965; Heertjes, Verloop, and Willems 1970; Oki, Walawender, and Fan 1977; Nguyen and Grace 1978; Raso and Tirabasso 1983; Lin, Chen, and Chao 1985). These measurement techniques can essentially be classified into three calegories: (1) using a small sensor to detect particle momentum in the flow path, (2) following the track of a tracer particle (i.e., radioactive tracer technique), and (3) atatistical correlation of particle movement as observed by optical fibers. However, because of the failure of the experimental idea and the difficulty involved in analyzing the data, none of these techniques has been successfully applied for the systematic measurement of the stochastic and transient forces of fuidized particles. Recently, Kono and coworkers (1987) described $a$ new experimental idea and technique for measuring the forces and the kinetic collision energy in gas-8olid fluidized beds using fracture-gensitive tracer particles of known mechanical strength. This gives a direct method to evaluate the kinetic performance of fluidized particles.

Solid particles move stochastically through a fluidized bed. Their motion is a function of position and time. In other words, the motion of fluidized particles is tranoient and not periudic. Therefore, a force distribution is imposed in a fluidized bed at each specific location for a certain time interval. The relatively large forces (near the maximum) in the distribution seem to be responsible for the erosion and attrition in fluidization systems. In this study, the fracture-sensitive tracer-particle method, piezoresistive strain-gauge 
method, and pressure fluctuation method are being simultaneously developed to investigate the kinetic behavior of solid particles in fluidized beds. Because fracture-sensitive tracer particles in a fluidized bed are exposed to a wide distribution of forces, the force that destroys the particles must be the prevailing maximum force at a given fluidization conditon. This method is appropriate to detect the maximum possible force of solid particles in fluidized beds. Consequently, the maximum force will simply be referred to as the "kinetic force." The piezoresistive strain-gauge method (using a Piezorton sensor) messures the local force and its time-dependent fluctuation with respect to a space-fixed probe. The force distribution of solid particles at a specific location in a fluidized bed can be obtained by this method. The pressure fluctuation method provides overall hydrodynamic information on the gas phase and will be correlated to the kinetic behavior of fluidized particles. 


\subsection{METHODOLOGY}

During the past year, the fracture-sensitive tracer-particle method was developed and applied to investigate the effects of particle size, superficial gas velocity, bed height, bed diameter, and bed configuration on the kinetic behavior of solid particles in fluidized beds. Quantitative data and comprehensive information (including a video observation of the destruction of the fracture-sensitive tracer particles in a two-dimensional fluidized bed) were obtained. A Piezotron sensor and PC data-acquisition system were also developed and are being used to measure the force distribution in fluidized beds.

\subsection{The Fracture-Sensitive Tracer-Particle Method}

\subsubsection{Preparation and Calibration of Fracture-Sensitive Tracer Particles}

Fracture sensitive tracer particles were prepared using a special pelletization technique. This technique is based on the theoretical equations derived by Rumpf (1958) and Hiramatsu et al. (1965) for the preparation of solid-liquid two phase granules. According to Rumpf, the tensile strength of a granule caused by the capillary forces is given by

$$
\sigma=6(1-\varepsilon) \frac{\gamma}{d},
$$

where

$\sigma:$ tensile strength of fracture-sensitive tracer particles [Pa],

$\varepsilon$ : porosity of fracture-sensitive tracer particles $[-]$,

$\gamma$ : surface tension of liquid $[\mathrm{N} / \mathrm{m}]$, and

d: diameter of primary particles [m].

Equation 1 was verified experimentally using the tensile-strength measurement equipment in our laboratory. The equipment utilizes a split-cell design by Hartley and Parfitt (1984), and is described as follows:

"The cell is supported on very low friction bearings and connected to a force transducer. One half of the cell is held secure while the other half is pulled away. The force transducer measures the force necessary to separate the cell."

Using this equipment, the tensile strength of glass bead powders ( $d=$ $256,76$, and $35 \mu \mathrm{m})$ with binding liquids $(\gamma=72,47$, and $27 \mathrm{dyn} / \mathrm{cm})$ was measured. Figure 1 shows the experimental tensile strength versus the theoretical prediction using Rumpf's equation. Figure 1 shows the good agreement.

Hiramatsu et al. (1965) proposed a correlation to calculate the compressive force that breaks a 8 pherical granule. Hiramatsu's tensile strength data yields the following equation: 


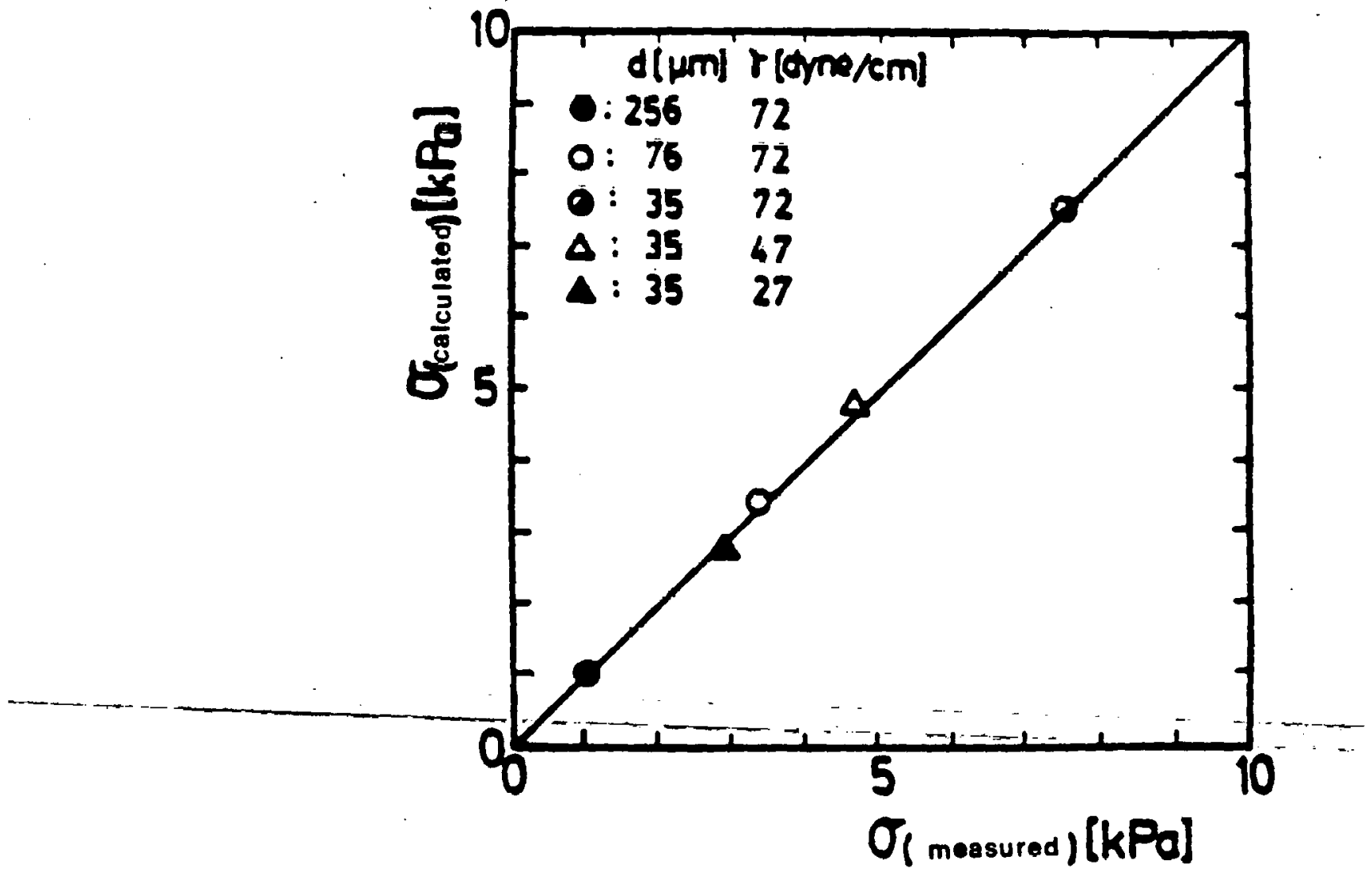

Figure 1. Experimental Verification of Rumpf's Equation 


$$
F=\frac{\pi D^{2}}{2.8} \sigma
$$

where

$$
D=\left(\frac{6}{\pi} \frac{\omega}{(1-\varepsilon) \rho_{P}+\varepsilon \rho_{L}}\right)^{1 / 3}
$$

and where

F: durable compressive force of the fracture-sensitive tracer particle $[\mathrm{N}]$,

D: diameter of the fracture-sensitive tracer particle [m],

$\sigma:$ tensile strength of the fracture-sensitive tracer particle [Pa],

W: mass of the fracture-sensitive tracer particle [kg],

$\rho_{\mathrm{p}}$ : liquid denaity $\left[\mathrm{kg} / \mathrm{m}^{3}\right]$, and

$\rho_{\mathrm{L}}$ : primary particle density $\left[\mathrm{kg} / \mathrm{m}^{3}\right]$.

By combining Equations 1 and 2, the compressive force that breaks a capillary-state granule can be expressed as

$$
F[N]=\frac{6}{2.8} \pi(1-\varepsilon) \underset{d}{d}\left(\frac{6}{\pi} \cdot \frac{w}{(1-\varepsilon) p_{p}+\varepsilon \rho_{L}}\right)^{2 / 3} .
$$

To prove the validity of Equation 3, a capillary-8tate granule (fracturesensitive tracer particle) was prepared and its mechanical strength was measured. The calculated compressive forces from Equation 3 and experimental data are compared in Figure 2. They are in good agreement.

Fracture sensitive tracer particles with varjous strengths $(0.3-8.6$ $\mathrm{kPa}$ ) were prepared by changing the ourface tension of the binding liquid and the primary particle diameter. The surface tension of liquida was controlled by adding ourfactant to water. The primary particle size of glass beads forming the granules ranged from 35 to $1000 \mu \mathrm{m}$. The voidage of the particles was experimentally determined at approximately 30 percent for all experiments. The weight of the particles was also controlled to be constant for all experiments. A rotating granulator was used to prepare fracture-sensitive tracer particles at the designed mechanical strength.

\subsubsection{Correlation Between the Durable Compressive Force and the Durable Impact Bnergy of Fracturo-Sensitive Tracer Particles}

The compressive strength of fracture-sensitive tracer particles has been determined, but these measurements were made in the static condition. It is necessary to determine the dynamic impact energy that causes the break of fracture-sensitive tracer particles during collision (durable impact energy of a granule). 


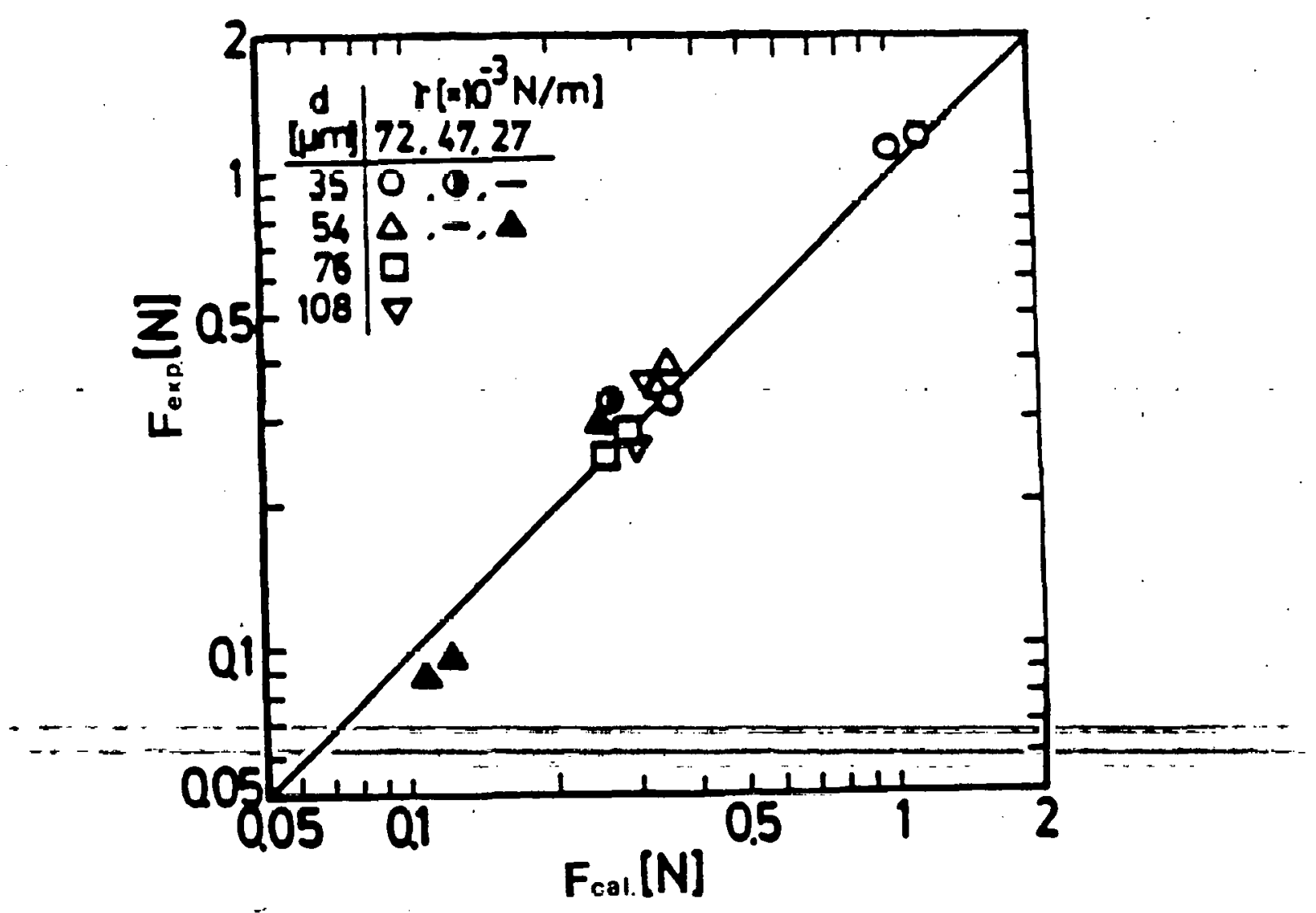

Figure 2. Expuriūentel Verificotion of Hiramatsu's Equation 
The static compressive force that breaks such a particle (durable compressive force of a granule) was determined using Equation 3. One preweighed, fracture-sensitive tracer particle with a known durable compressive force was dropped on a large stainless steel plate. This particle was dropped from an increasingly greater height until a crack appeared on the tracer particle. The effect of air resistance on the dropping granule was neglected, and the durable impact energy was assumed to be the potential energy as given by

$$
E=w_{g h},
$$

where

E: durable impact energy of the fracture-sensitive tracer particle [ $\mathrm{J}$ ],

W: mass of the fracture-sensitive tracer particle [kg],

g: gravitational constant $\left[\mathrm{m} / \mathrm{s}^{2}\right]$, and

h: minimum height at which first crack appears [m].

Figure 3 shows a plot of durable compressive force versus durable impact energy for fracture-sensitive tracer particles in a glass bead system. Regression analysis gives the following empirical correlation:

$$
E[J]=5.9849 \times 10^{-3} F[N] .
$$

Applying Equations 3 and 5, the mechanical properties of a fracturesensitive tracer particle (durable compressive force and durable impact energy) can be obtained. Typical examples of physical and mechanical properties of such particles are shown in Table 1.

Table 1. Physical and Mechanical Properties of Fracture-Sensitive Tracer Particles

\begin{tabular}{cccccc}
\hline $\begin{array}{c}d \\
(\mu \mathrm{m})\end{array}$ & $\begin{array}{c}\gamma \times 10^{3} \\
(\mathrm{~N} / \mathrm{m})\end{array}$ & $\begin{array}{c}\mathrm{D} \\
(\mathrm{m})\end{array}$ & $\begin{array}{c}\sigma \\
(\mathrm{kPa})\end{array}$ & $\begin{array}{c}F \times 10^{2} \\
(\mathrm{~N})\end{array}$ & $\begin{array}{c}\mathrm{E} \times 10^{4} \\
(\mathrm{~J})\end{array}$ \\
\hline 35.0 & 27 & 6.2 & 2.70 & 8.15 & 4.88 \\
35.0 & 47 & 6.2 & 4.75 & 14.34 & 8.58 \\
35.0 & 72 & 6.2 & 8.64 & 37.23 & 22.30 \\
54.0 & 72 & 6.2 & 5.60 & 24.13 & 14.40 \\
76.5 & 72 & 6.0 & 3.95 & 16.07 & 9.62 \\
107.5 & 72 & 6.0 & 2.81 & 11.44 & 6.85 \\
168.5 & 72 & 6.4 & 1.80 & 8.24 & 4.93 \\
256.0 & 72 & 6.4 & 1.18 & 5.42 & 3.24 \\
362.5 & 72 & 6.9 & 0.83 & 4.44 & 2.66 \\
512.5 & 72 & 6.6 & 0.59 & 2.91 & 1.74 \\
1015.0 & 72 & 6.9 & 0.30 & 1.59 & 0.95 \\
\hline
\end{tabular}




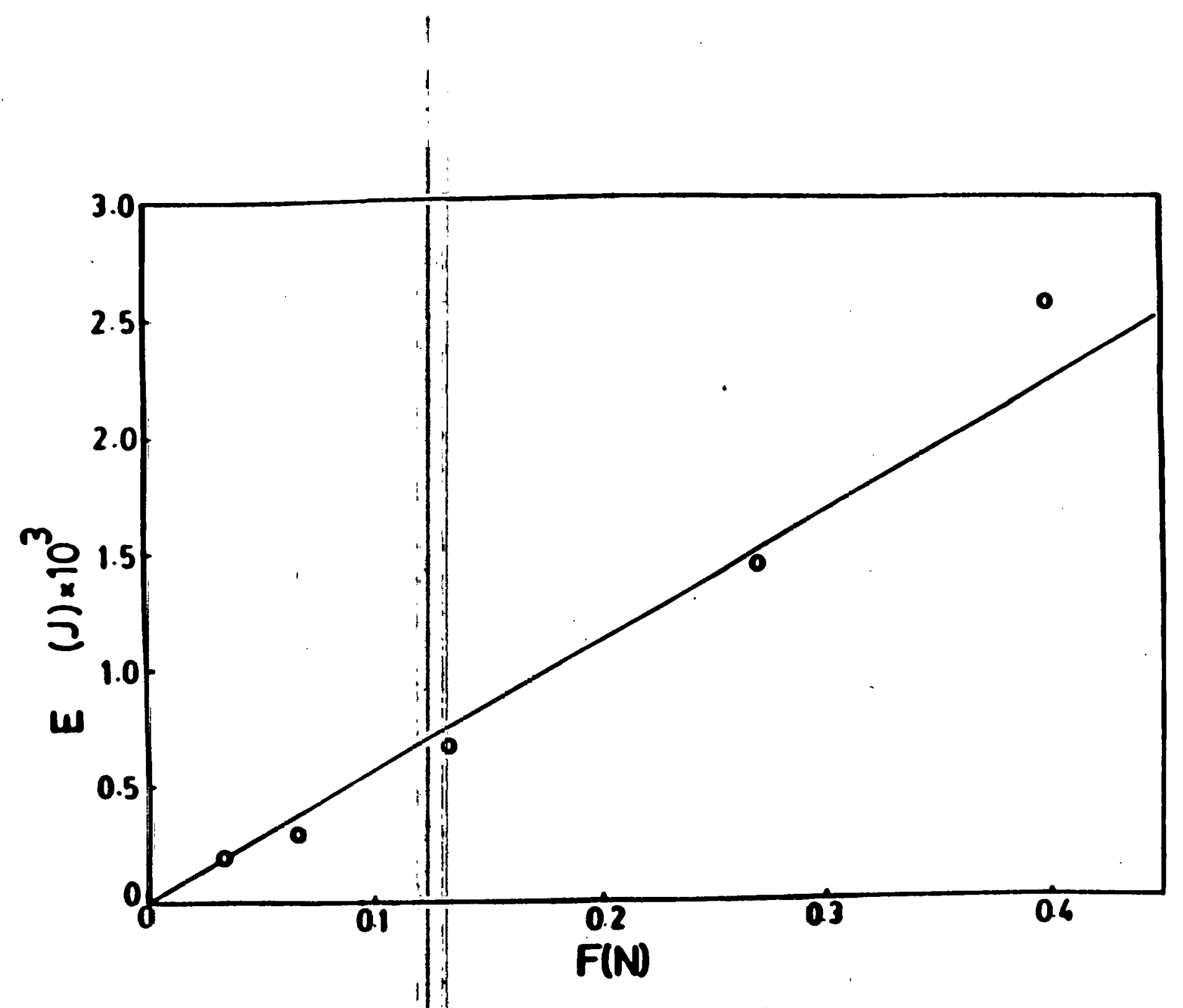

Figure 3. Experimental Relationghip Between Dynamic Impact Energy and Durable Static Compressive Force 


\subsubsection{Experimental Procedure}

The experimental setup of the fluidization system is shown in Figure 4. The kinetic forces of solid particles in fluidized beds were delermined by the following procedure. About 8 to 12 preweighed, fracturesensitive tracer particles $\left(W_{j}\right)$, of uniform size and with known mechanical strength (durable compressive force and durable impact energy), were placed in a fluidized bed at a given fluidization condition. After 2 minutes the air supply was stopped, and the amount of particles that survived in the fluidized bed $\left(W_{0}\right)$ was determined by careful sieving. The fluidizing air was humidified in order to prevent the granules fromdrying out. The time for fluidization was determined, based on the following considerations:

(1) The time for fluidization should be short enough that the effect of drying is negligible.

(2) The time for fluidization should be long enough to ensure that the fracture-sensitive tracer particles experience the kinetic forces prevailing in the bed.

(3) The time for fluidization should be chosen such that the experiment is time efficient.

It was determined by experiment that a period of about 2 minutes was satisfactory.

By plotting $U_{O} / U_{m f}$ versus $w_{O} / w_{i}$ (survival ratio of fracture-sensitive tracer particles after fluidization), the minimum value of $U_{o} / U_{m f}$ at which the particles of known strength were totally destroyed was determined. (See Figure 5.) At this value of $U_{0} / U_{m f}$, the kinetic force in the fluidized bed was considered to be equal to the durable compressive force of the fracture-sensitive tracer particle, F. Also at this value of $U_{0} / U_{m f}$, the dynataic impact energy of fluidized particles was assumed to be equal to the durable impact energy of the fracturesensitive tracer particles, E. By repeating the above experiment with fracture-sensitive tracer particles of different strengths, a plot of $U_{0} / U_{m f}$ versus $F$ can be generated. This experiment will be done at various fluidized particle sizes, bed configurations, and bed aspect ratios.

In this study, three circular fluidized beds (inside diameters of 0.108 $\mathrm{m}, 0.203 \mathrm{~m}$, and $0.292 \mathrm{~m})$, a spouted fluidized bed $(0.108 \mathrm{~m}$ I.D. fluidized bed with a $0.0254 \mathrm{~m}$ jet opening and 600 conical perforated gas distributor having holes of $1.5 \mathrm{~mm}$ diameter), a square fluidized bed $(0.108 \mathrm{~m} \times 0.108 \mathrm{~m})$, and a two-dimensional fluidized bed $(0.25 \mathrm{~m} \times 0.01$ m) were used. A sintering plate with a hole opening of $150 \mathrm{~mm}(100$ mesh) was usually used as the gas distributor. However, perforated plates with holes 1.0 and $1.5 \mathrm{~mm}$ in diameter and a bandage-covered wire screen were also used to study the gas distributor effect on the kinetic forces of solid particles in the fluidized bed. The fluidized media were glass beads, with the properties listed in Table 2. 


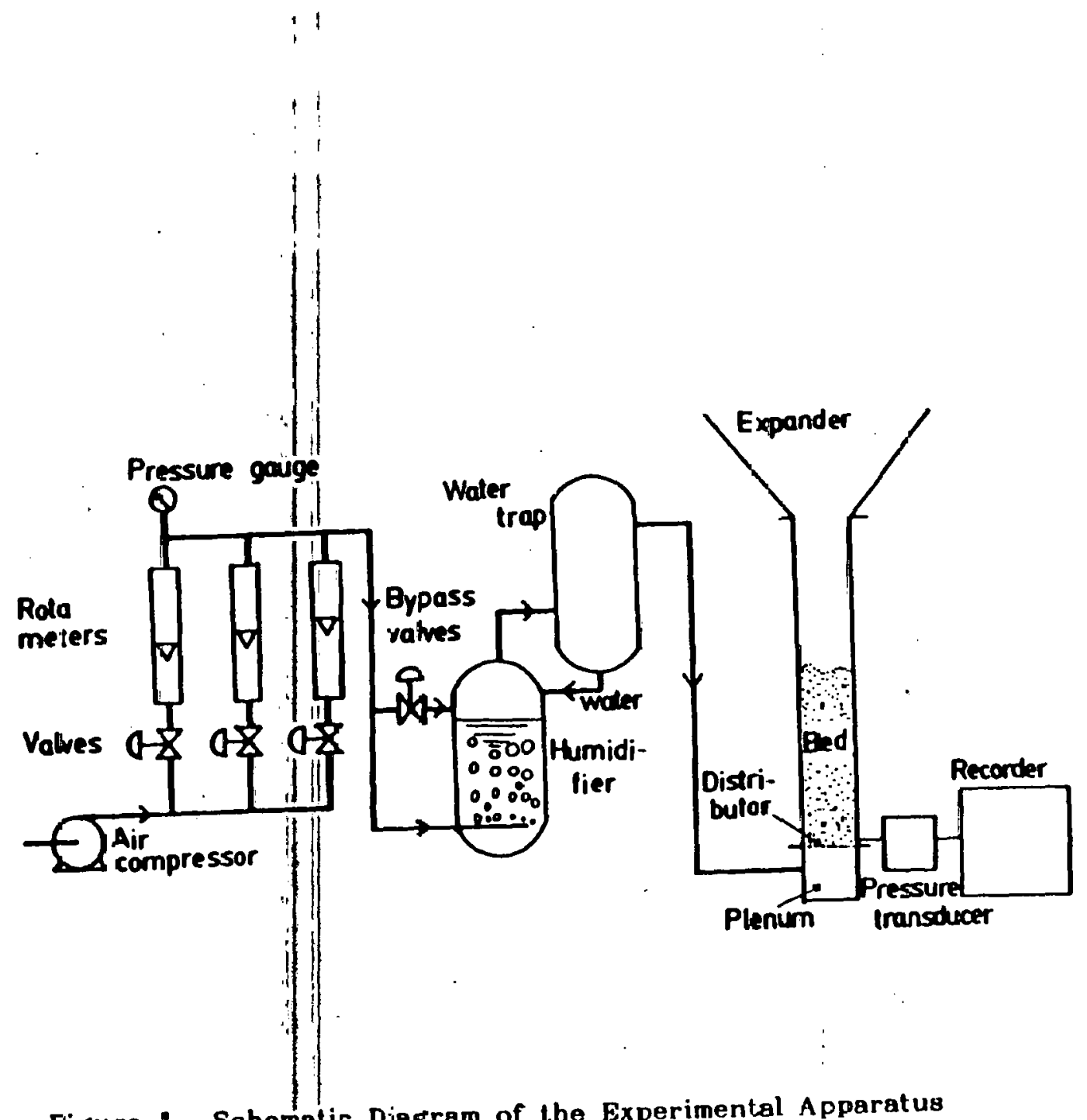

Figure 4. Schematic Diagram of the Experimental Apparatus 


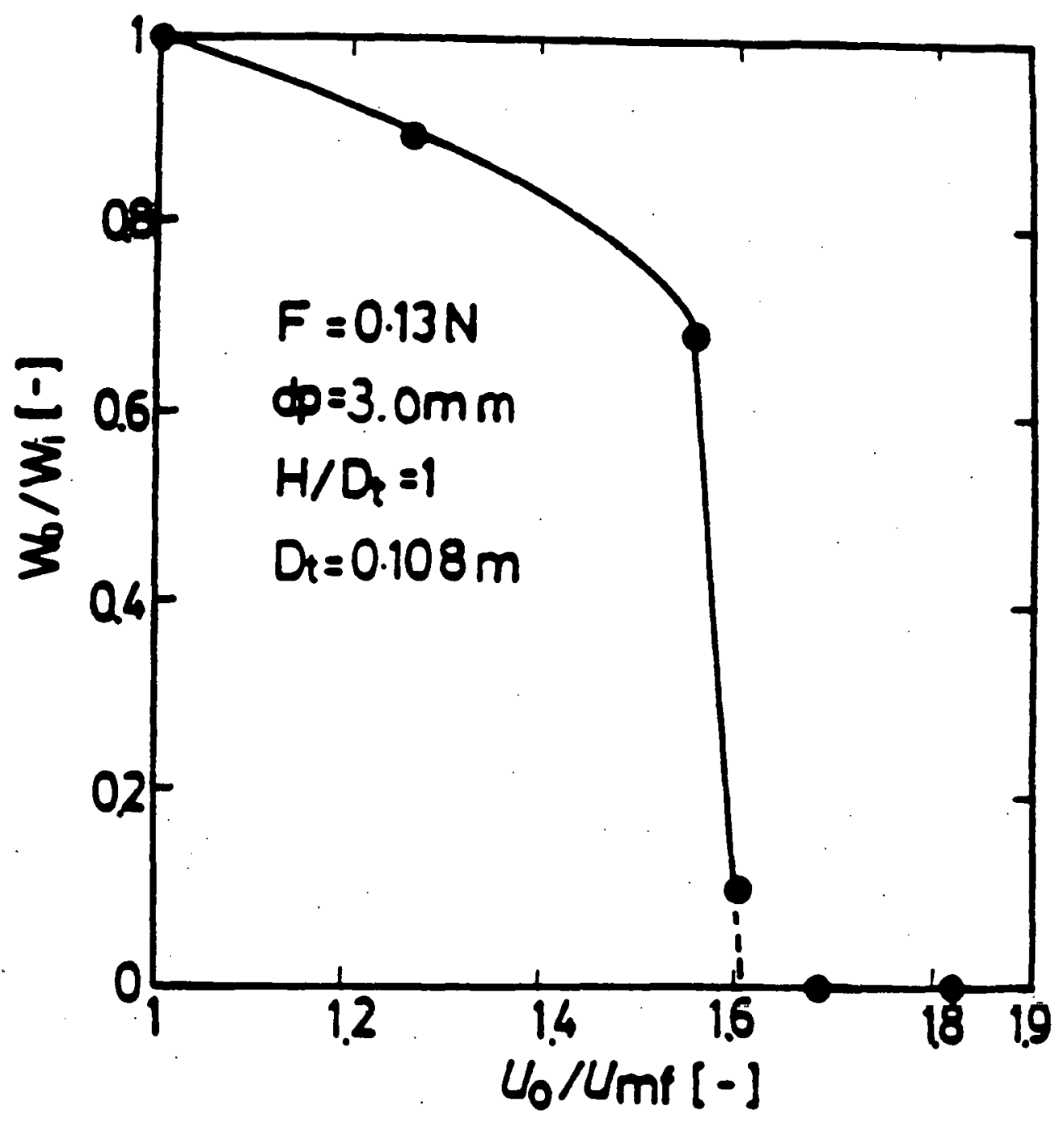

Figure 5. Estimation of the Minimum Value of Dimensionless Gas Velocity at Which Fracture-Sensitive Tracer Particles of Known Strength Were Totally Destroyed 
Table 2. Physical Properties of Glass Beads

\begin{tabular}{ccc}
\hline $\begin{array}{c}\text { AVERAGE PARTICLE } \\
\text { DIAMETER } \\
\mathrm{dp}(\mathrm{mm})\end{array}$ & $\begin{array}{c}\text { PARTICLE DENSITY } \\
\rho_{\mathrm{p}}\left(\mathrm{kg} / \mathrm{m}^{3}\right)\end{array}$ & $\begin{array}{c}\text { MINIMUM FLUIDIZATION } \\
\text { VELOCITY } \\
\mathrm{U}_{\mathrm{m} f(\mathrm{~m} / \mathrm{s})}\end{array}$ \\
\hline 2.18 & $2.49 \times 10^{3}$ & 1.36 \\
1.0 & $2.49 \times 10^{3}$ & 0.46 \\
0.5 & $2.52 \times 10^{3}$ & 0.22 \\
\hline
\end{tabular}

2.1.4 The Effect of Pluidizing-Air Bumidity on the Force Measurement

The humidity of the fluidizing air was maintained at a 90-percent relative humidity in a previous study (Kono, Soltani-Ahmadi, and Suzuki 1987) to prevent the fracture-sensitive tracer particles from drying and lu reduce the electrostatic chargo of the fluidized media. However, the water vapor in the fluidizing air may have condensed slightly on the surface of the fluidized glass beads at a relative humidity of 90 percent because of temperature variations in the experimental environment. Condensation results in an increase in interparticle force and retards the motion of the fluidized particles. According to our observation of glass bead systems $(d p=0.5 \sim 2.18 \mathrm{~mm}$ ), there was no significant electrostatic effect and the drying of tracer particles was negligible when the relative humidity of the fluidizing air was maintained above 50 percent.

Figure 6 shows the effect of the relative humidity of the fluidizing air on the survival ratio of fracture-sensitive tracer particles $\left(W_{0} / W_{j}\right)$. The kinetic forces of fluidized particles at relative humidities of 50,70 , and 90 percent were measured using the fracture-sensitive tracerparticle method in a $0.108 \mathrm{~m}$ I.D. fluidized bed. These results are shown in Figure 7. The experimental evidence-from Figures 6 and 7 shows that it is appropriate to maintain the relative humidity between 50 and 70 percent while measuring the force in a glass bead system. This will avoid the drying of tracer particles, the electrostatic effect, and water vapor condensation on the fluidized particles. Hereafter, the relative humidity of fluidizing air (at room temperature) will be maintained at 50 percent for all force measurement experiments.

\subsubsection{Video Observation of the Destruction of Fracture-Sensitive Tracer Particles in a Two-Dimenaional Fluidized Bed}

A video of the two-dimensional fluidized bod filmed by hich epeed camera shows the motion of a fracture-sensitive tracer particle and its destruction. The particle seems to be destroyed as it moves into the bubble-wake area. It has been reported that the wake has a different structure than that of the emulsion phase. A so-called "shedding" phenomenon existing in the wake creates traneient nuctuations and locally high forces. However, a more detailed investigation into the motion of the bubble and wake is necessary to reach conclusions. 


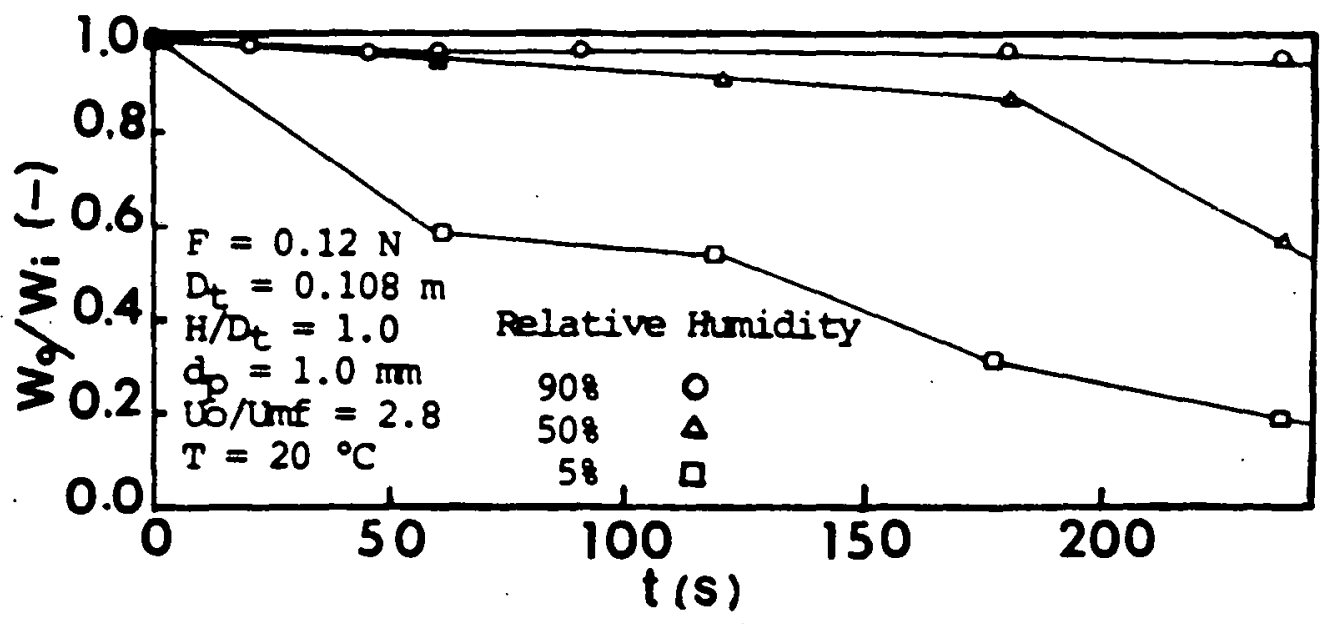

Figure 6. The Effect of the Relative Humidity of Fluidizing Air on the Survival Ratio of Tracer Particles 


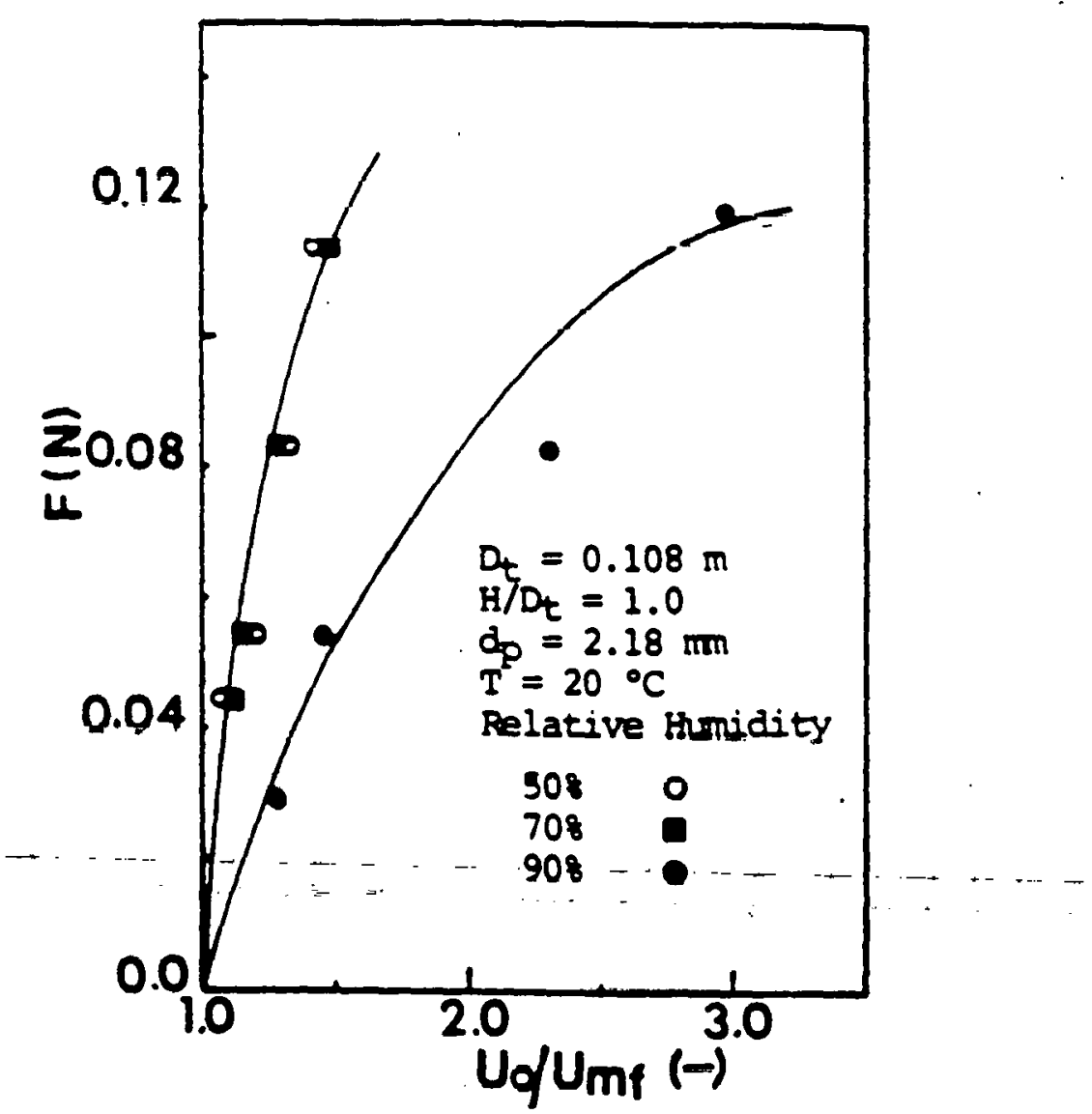

Figure 7. The Effect of the Relative Humidity of Fluidizing Air on the Prevailing Kinetic Forces in a Fluidized Bed 


\subsection{Piezoresistive Strain-Gauge Method}

\subsubsection{General Remarks}

The techniques for measuring solid-particle forces in fluidized beds that have been investigated 80 far are the fracture-sensitive tracerparticle method, the Piezotron sensor method, and the "bonded resistance" strain-gauge method. The first method was developed in this research and has been used to evaluate the kinetic forces of solid particles in fluidized beds for various bed sizes, heights, and configurations.

The strain gauge can measure mechanical quantities and produce an electrical signal. Strain gauges, such as the piezoresistive, semiconductor, carbon-resistive, metallic wire, and foil resistance types, depend on the proportional variance of electric resistance to strain. The Piezotron sensor (a piezoresistive strain gauge) and a "bonded resistance" strain gauge were tested. The term "bonded resistance" strain gauge can apply to a nonmetallic (semiconductor) or metallic (wire or foil) gauge. A metallic gauge was used in this work. The fundamental mechanism of force-strain response is the same for the piezoresistive and bonded resistance strain gauges. To measure small forces (such as the kinetic forces of fluidized particles), the bondedresistance strain gauge is attached to the area of the sensor that has high strain. In this setup, the bonded-resistance strain gauge has no orientation in the force measurement and is rather difficult to use at present. The Piezotron 'sensor has a one-dimensional force measurement capability. Therefore, we decided that this study should concentrate on using the Piezotron sensor for force measurements.

\subsubsection{Design and Calibration of the Piezotron Sensor}

A one-dimensional piezoelectric load cell (Piezotron sensor) made by Kistler, Inc., was used as the force transducer in this study. The piezoelectric crystal in the Piezotron sensor was connected to a needle probe, as shown in Figure 8. In the experiments, the load cell was fixed to a stationary support; the needle probe, covered by a sheath, was inserted into the fluidized bed to measure the impact forces of the fluidized particles. As a fluidized particle collides with the needle probe, a mechanical stress is imposed on the crystal and an electric voltage is generated by the piezoelectric effect. However, any relative motion between the load cell and the needle probe also generates electric voltages. The electric voltages resulting from the vibration of the fluidized column are system noises. The Piezotron sensor must be installed without contacting the fluidized column to avoid gystem noises. Distinguishable aignals can be obtained by inserting the Piezotron sensor vertically, since the Piezotron sensor does not contact the fluidized column and has a higher sensitivity in this setup. The setup of the Piezotron sensor apparatus is shown schematically in Figure 9. The experimental results can be used to investigate the kinetic force distributions of solid particles in fluidized beds. 
(a)

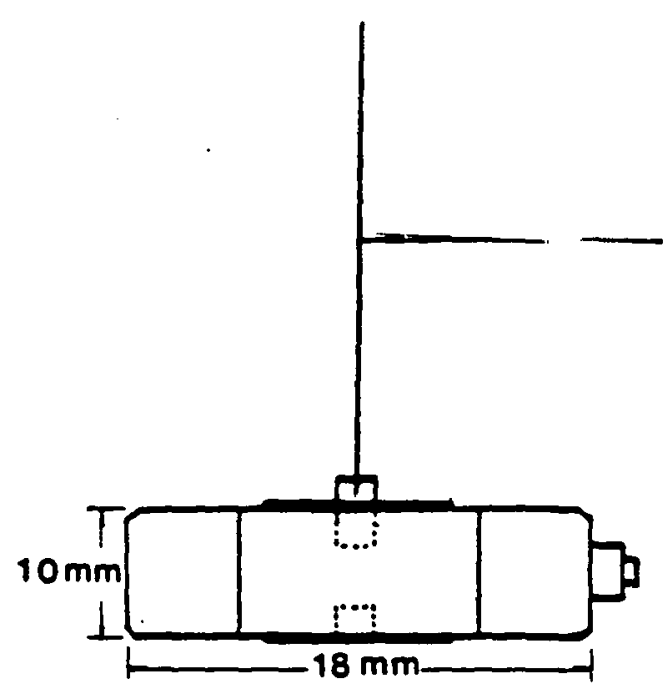

(b)

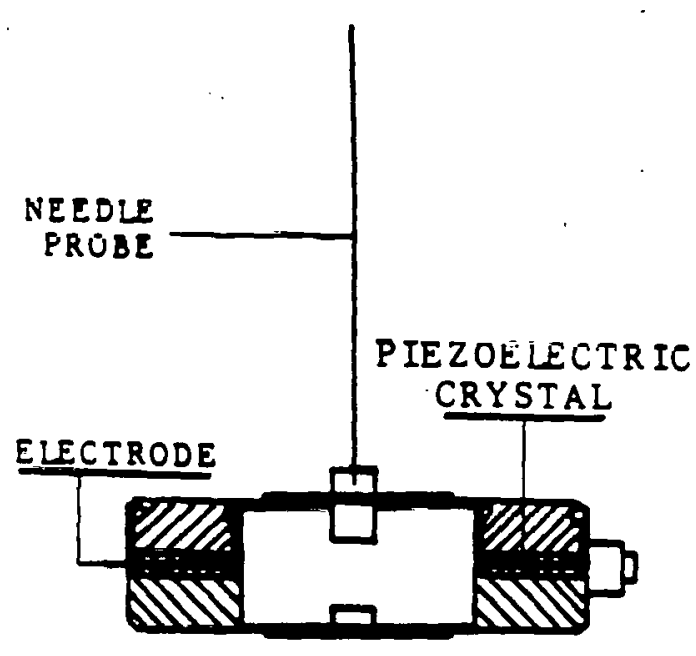

(a) Outside Vicw of Piezotron Sensor

(b) Cross Section View of Piezotron Sensor

Figure 8. The Structure of the Piezotron Sensor 


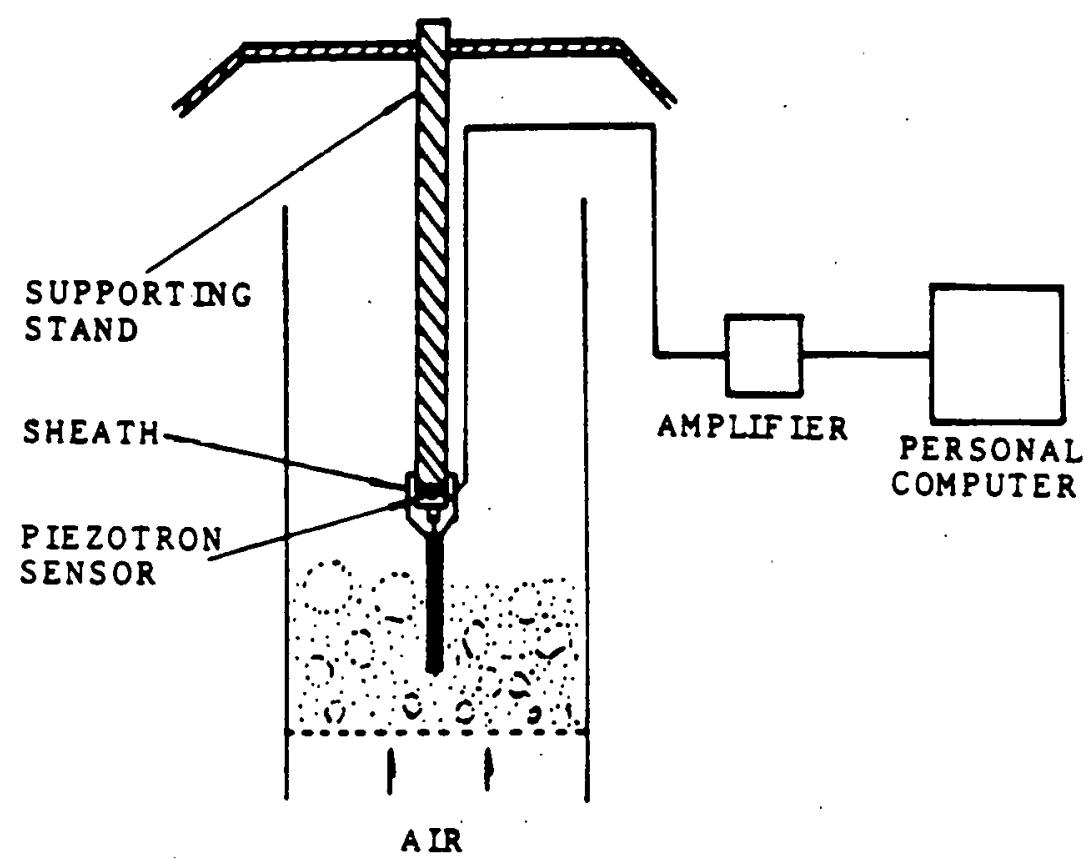

Figure 9. Schematic Diagram of the Piezotron Sensor Apparatus 


\subsubsection{Development of Data Acquisition System}

To facilitate data taking and processing of solid-particle force measurements with the Piezotron sensor, programs for a data acquisition system were developed. The developed system can store up to 20,000 data points at any sampling rate between 10 and $28,000 \mathrm{~Hz}$, plots the data on a screen or paper, and calculates the force distribution in fluidized beds. This system is being used in this study. Preliminary experiments will be done to determine the optimal sampling rate and sampling time for gathering data.

As a test of the data acquisition system, a set of data was gathered at a sampling rate of $1000 \mathrm{~Hz}$ for a period of 10 seconds. Figure 10 shows preliminary results of the measurement of local forces of anlid particles ( $d p=1.0 \mathrm{~mm}$ ) in a fluidized bed at a superficial gas velocity of $1.0 \mathrm{~m} / \mathrm{s}$. The measurements were made at the center of the $0.203 \mathrm{~m}$ I.D. fluidized bed and at $a$ height of ahout $1 \mathrm{~cm}$ below the surface of the fluidized bed. Figure 11 shows the force distribution calculated using the developed prograri and the data sliuwn in Figure 10. Further experiments seem to be necessary to assess the reliability of this measuring technique. 


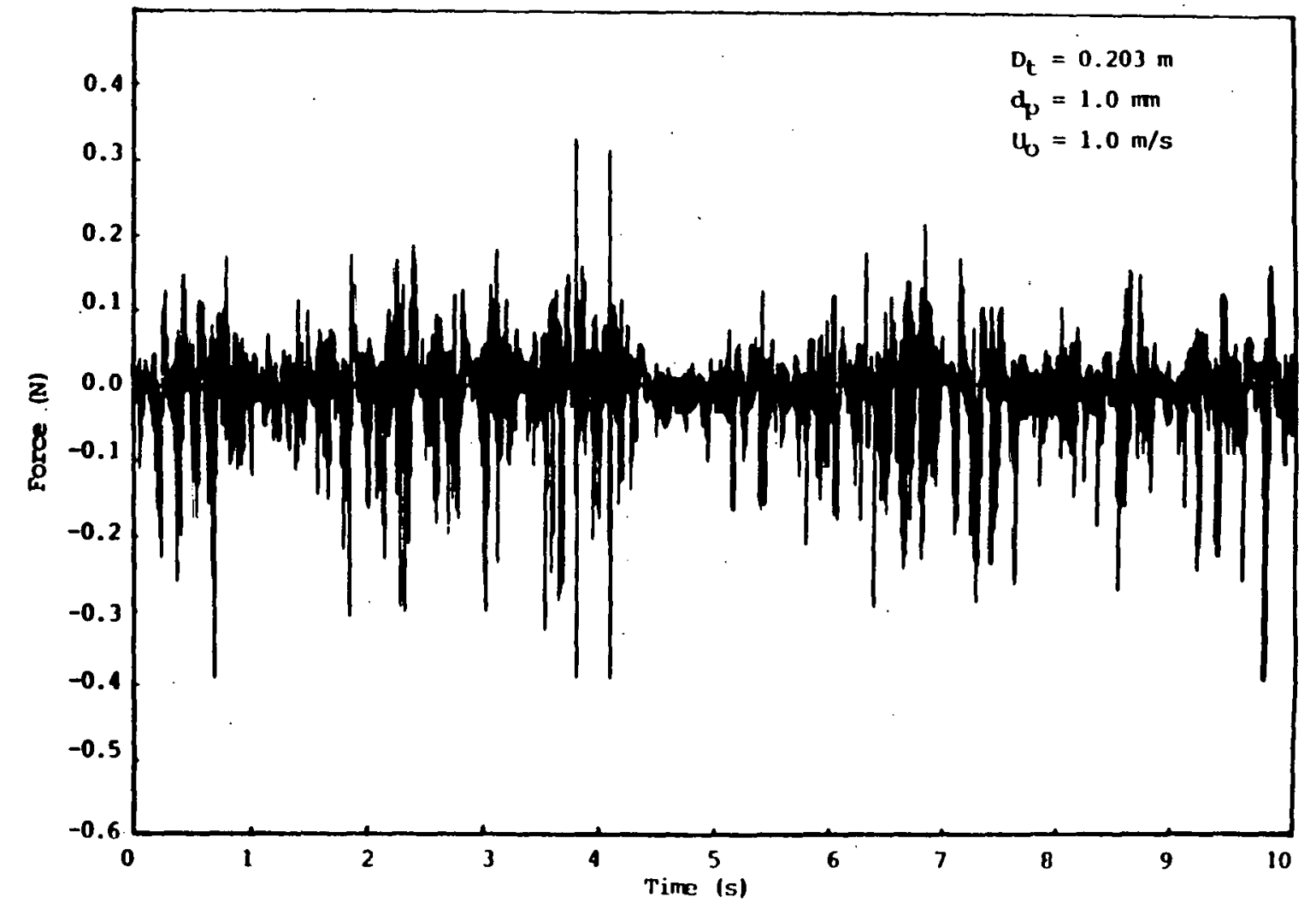

Figure 10. Force Signals Obtained From the Piezotron Sensor 


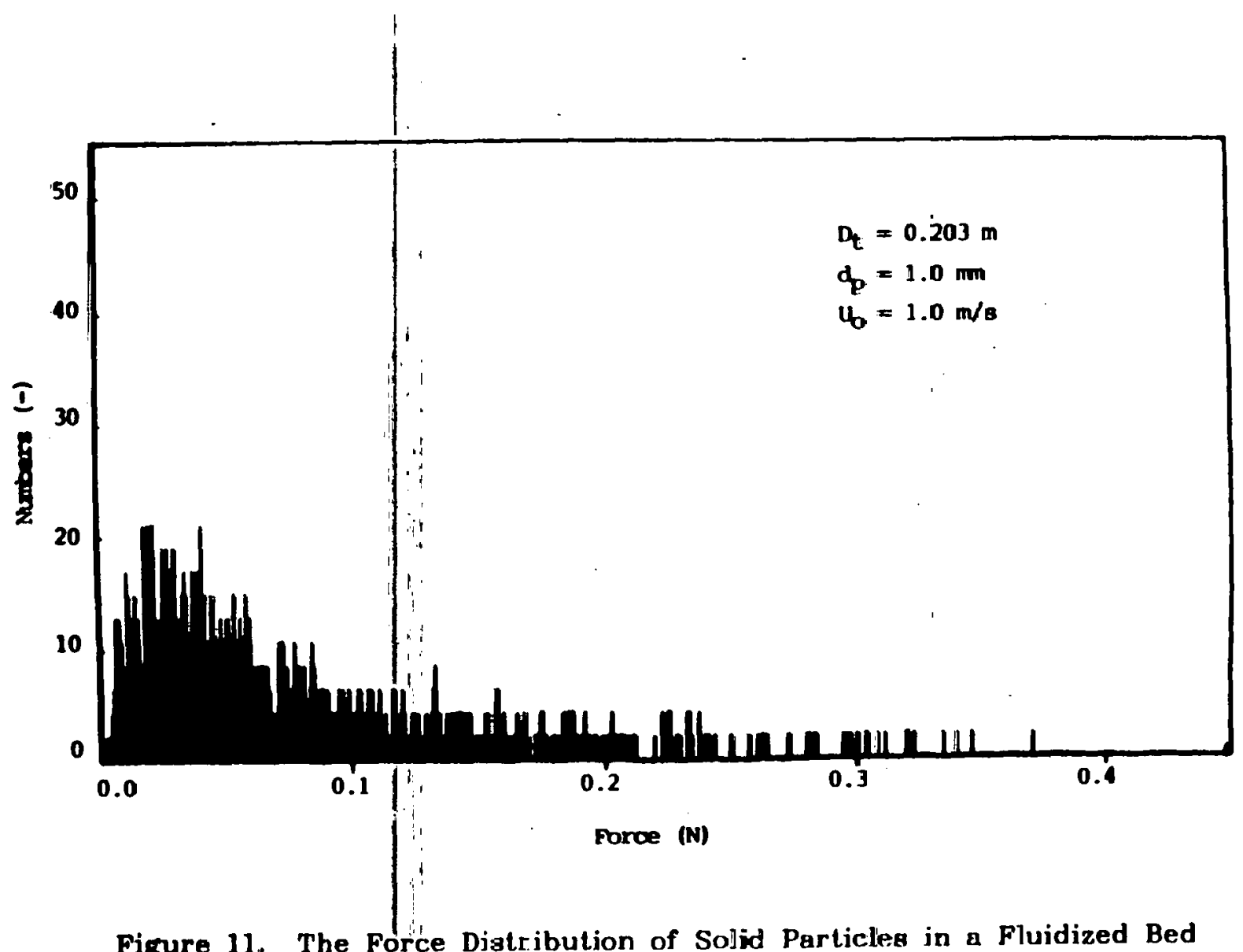

Figure 11. The Force Diatribution of Solid Particles in a Fluidized Bed

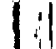




\subsection{RESULTS AND DISCUSSION}

Many measurements of force were made during the last year using the fracture-sensitive tracer-particle method. In general, the kinetic forces of solid particles increase with larger particle sizes, bed heights, and superficial gas velocities, as shown in Figures 12, 13, and 14. A tendency for the kinetic force to reach a maximum at each fluidization condition as the superficial gas velocity increases can also be seen. When the maximum kinetic force is reached, the fluidization condition seems to change from slugging (the presence of large bubbles and unstable fluidization) to turbulent. The scale-up effect has been studied at a constant bed aspect ratio $\left(H / D_{t}\right)$, as shown in figure 15. It seems that the kinetic forces of fluidized particles increase with the bed diameter when the bed aspect ratio remains constant. However, the increase in kinetic forces of fluidized particles may be because of an increase in the bed diameter, bed height, or both. Figure 16 shows that the kinetic forces of solid particles $(\mathrm{dp}=1.0 \mathrm{~mm}$ ) were about the same in fluidized beds of $0.108 \mathrm{~m}, 0.203 \mathrm{~m}$, and $0.292 \mathrm{~m} \mathrm{I.D.} \mathrm{when}$ measured at the same bed height of $0.203 \mathrm{~m}$. But at a bed height of $0.292 \mathrm{~m}$, the kinetic forces of solid particles in the $0.108 \mathrm{~m}$ I.D. fluidized bed were higher than those in $0.203 \mathrm{~m}$ and $0.292 \mathrm{~m}$ I.D. fluidized beds, as shown in Figure 17. This shows that the slugging phenomenon, which is assumed to be responsible for the kinetic forces of fluidized particles, may be significantly affected by the bed diameter when relatively coarse particles are present at bed heights greater than $0.292 \mathrm{~m}$. However, bed diameter does not appear to significantly affect the kinetic forces of fluidized particles when it is larger than $0.203 \mathrm{~m}$ I.D. It must be noted that the effect of bed diameter on the slugging phenomenon is less than that of bed height, and becomes negligible when the diameter is larger than $0.203 \mathrm{~m}$ I.D.

In general, the pressure drop across a gas distributor increases with the superficial gas velocity. The relationship between the pressure drop across a gas distribulor and the superficial gas velocity for the three types of gas distributors used in this study is shown in Figure 18. At lower gas velocities, different types of gas distributor did not show an effect on the kinetic forces of solid particles in fluidized beds. (See Figure 19.) But at higher gas velocities, the gas distributor affected the kinetio forces of fluidized particles. (See Figure 20.) It can be seen that the pressure drop across the gas distributor can cause a difference in the kinetic forces of fluidized particles. At high gas velocities, the porous-plate gas distributor (o 100 mesh) has the same effect on the kinetic forces of fluidized particles as the perforated-plate gas distributor with holes $1.0 \mathrm{~mm}$ in diameter.

The kinetic behavior of solid particles in a $0.108 \mathrm{~m}$ I.D. apouted fluidized bed was also investigated. The spouted fluidized bed has a $0.0254 \mathrm{~m}$ jet opening and a 600 , conical, perforated gas distributor with holes $1.5 \mathrm{~mm}$ in diameter. The volumetric now ratio of fluidizing air through the jet opening (X), fluidized particle size, superficial gas velocity, and bed height were systematically studied with respect to how these parameters affect the kinetic forces of solid particles in a spouted fluidized bed. Figure 21 shows that the effects of fluidized particle size, superficial gas velocity, and bed height are the same on 


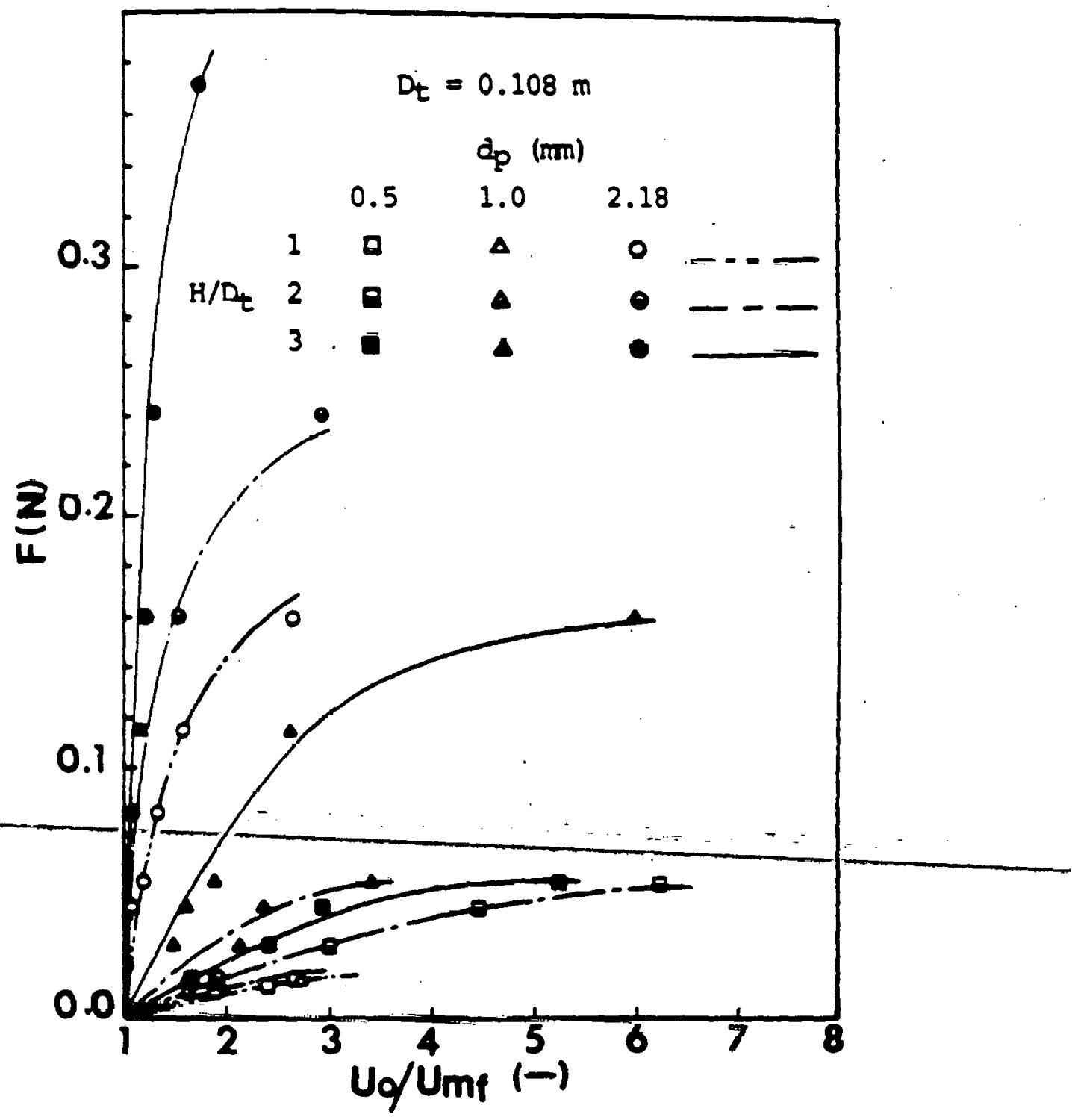

Figure 12. The Effecta of Particle Size, Bed Aspect Ratio, and Gas Velocity on the Prevailing Kinetic Forces in a $0.108 \mathrm{~m}$ I.D. Fluidized Bed 


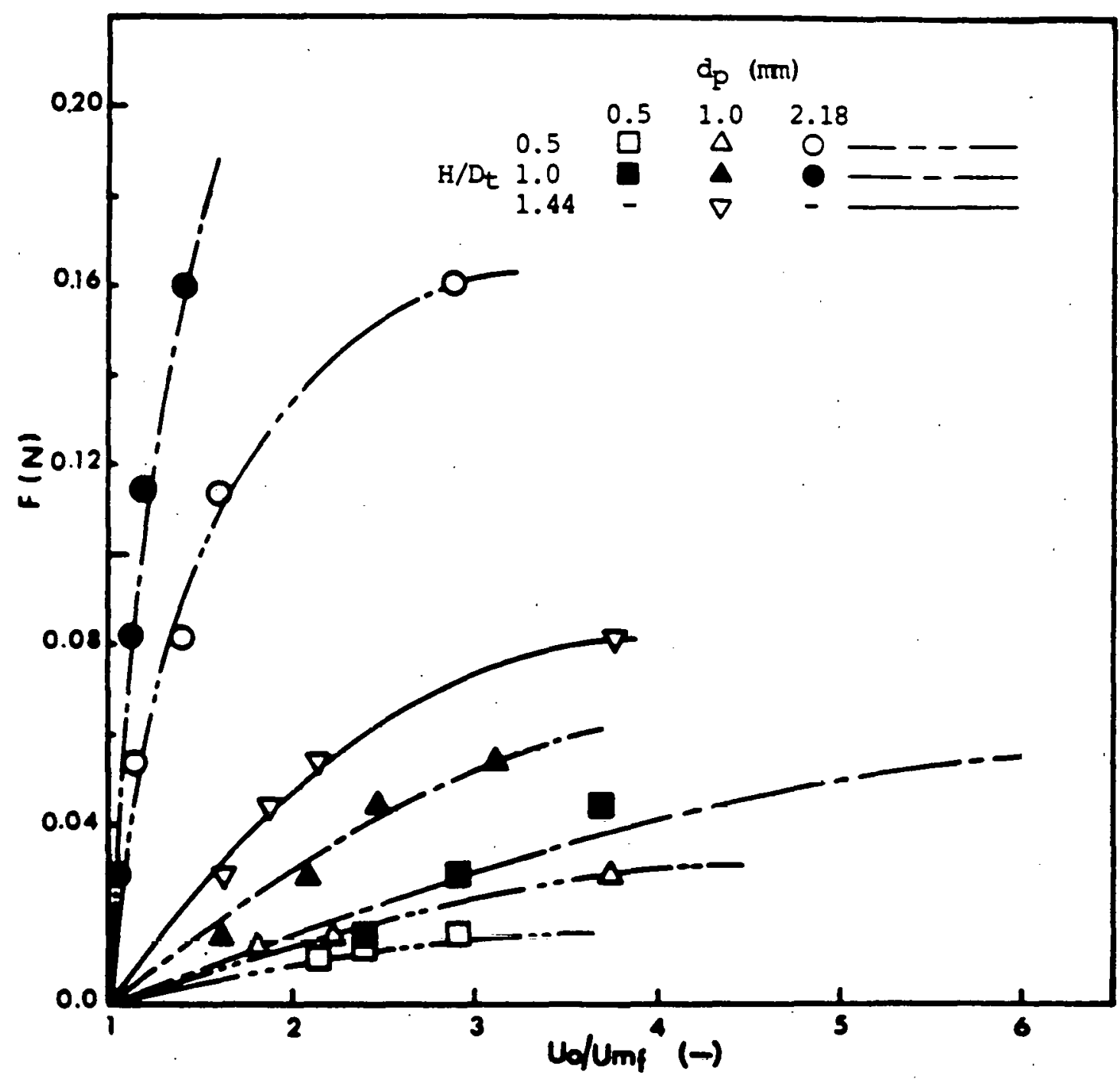

Figure 13. The Effects of Particle Size, Bed Aspect Ratio, and Gas Velocity on the Prevailing Kinetic Forces in $0.203 \mathrm{~m}$ I.D. Fluidized Bed 


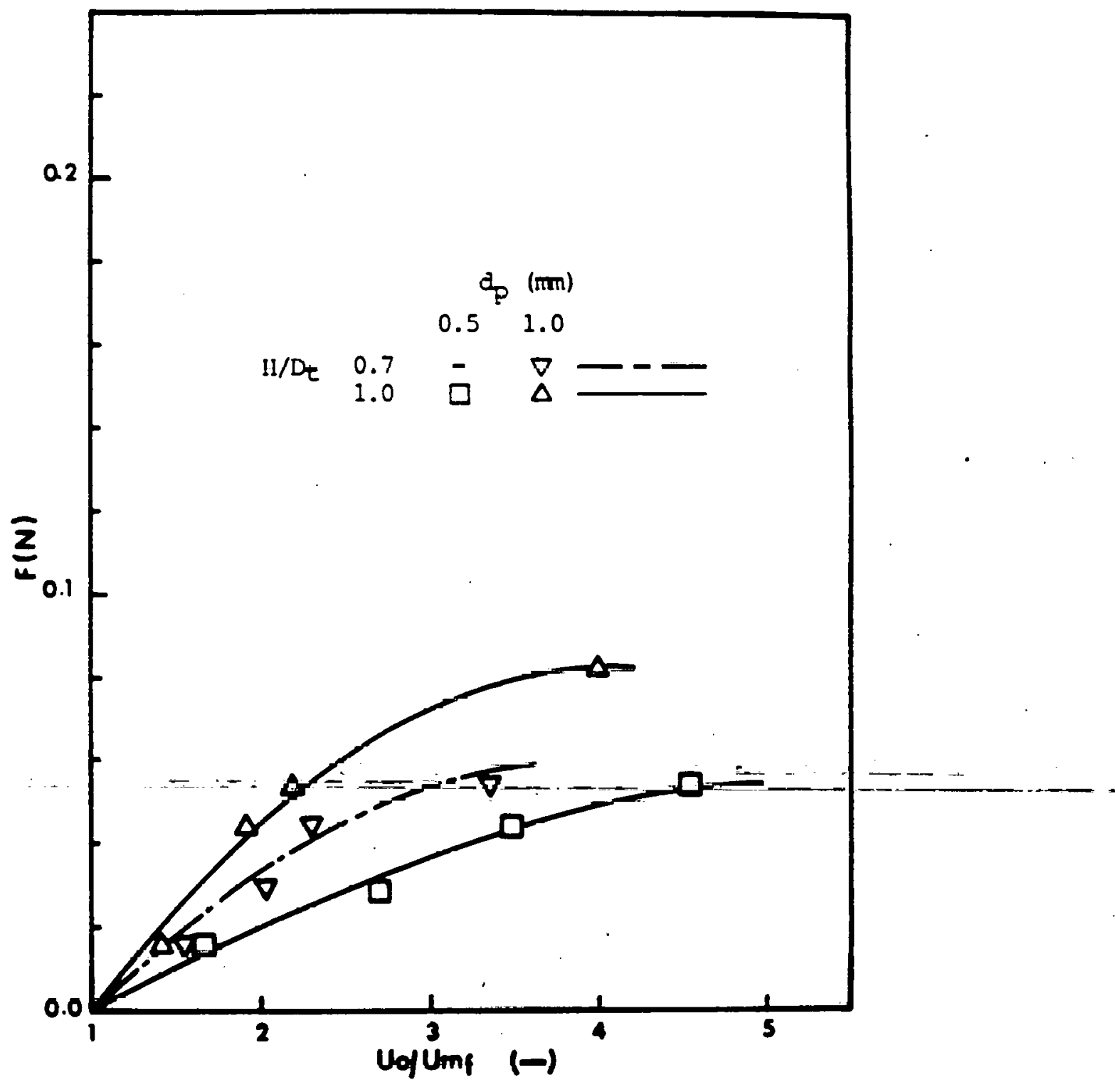

Figure 14. The Effects of Particle Size, Bed Aapect Ratio, and Gas Velocity on the Prevailing Kinetic Forces in $80.292 \mathrm{~m}$ I.D. Fluidized Bed 


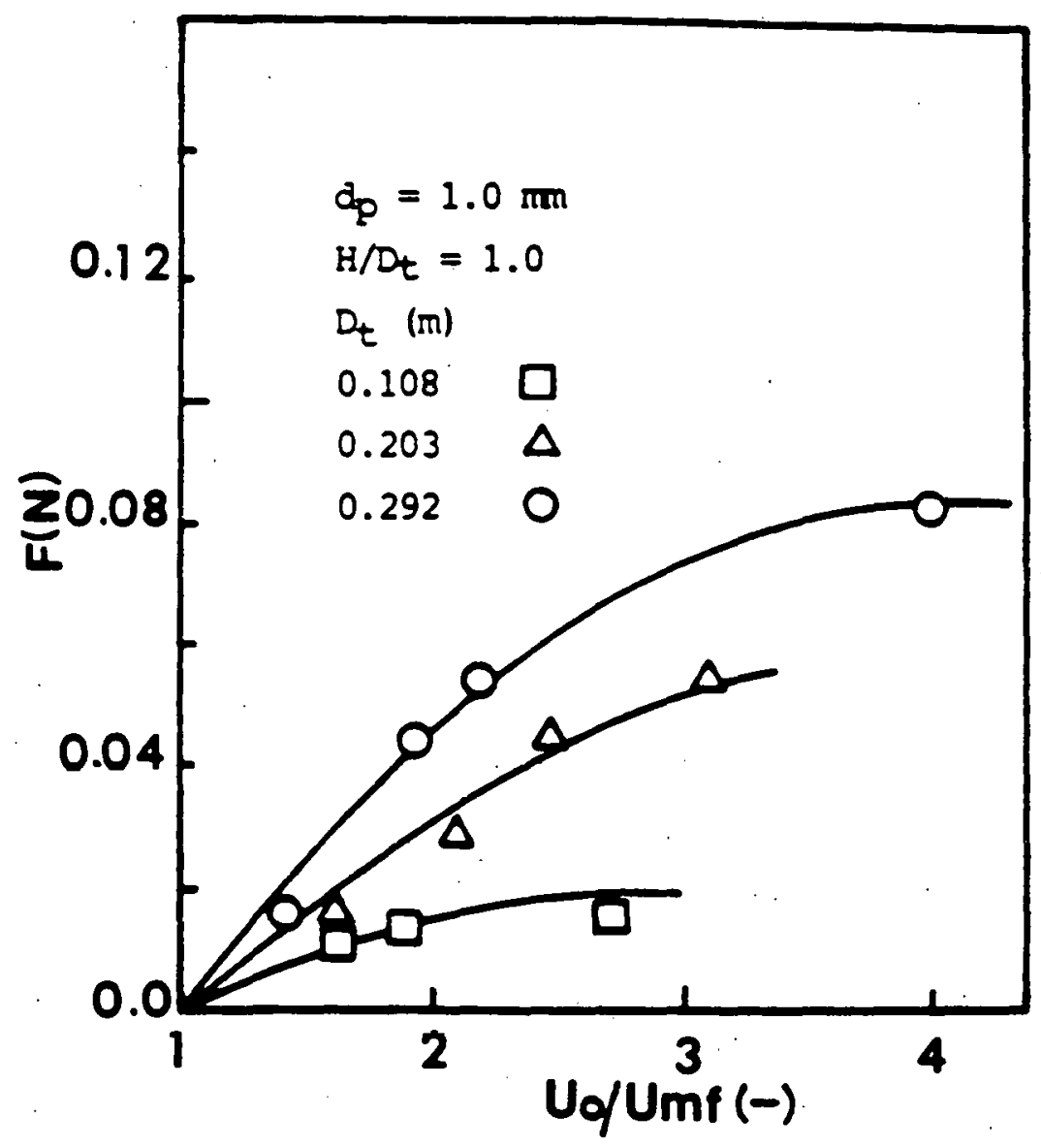

Figure 15. The Effect of Bed Diameter on the Prevailing Kinetic Forces in Fluidized Beds at a Constant Bed Aspect Ratio 


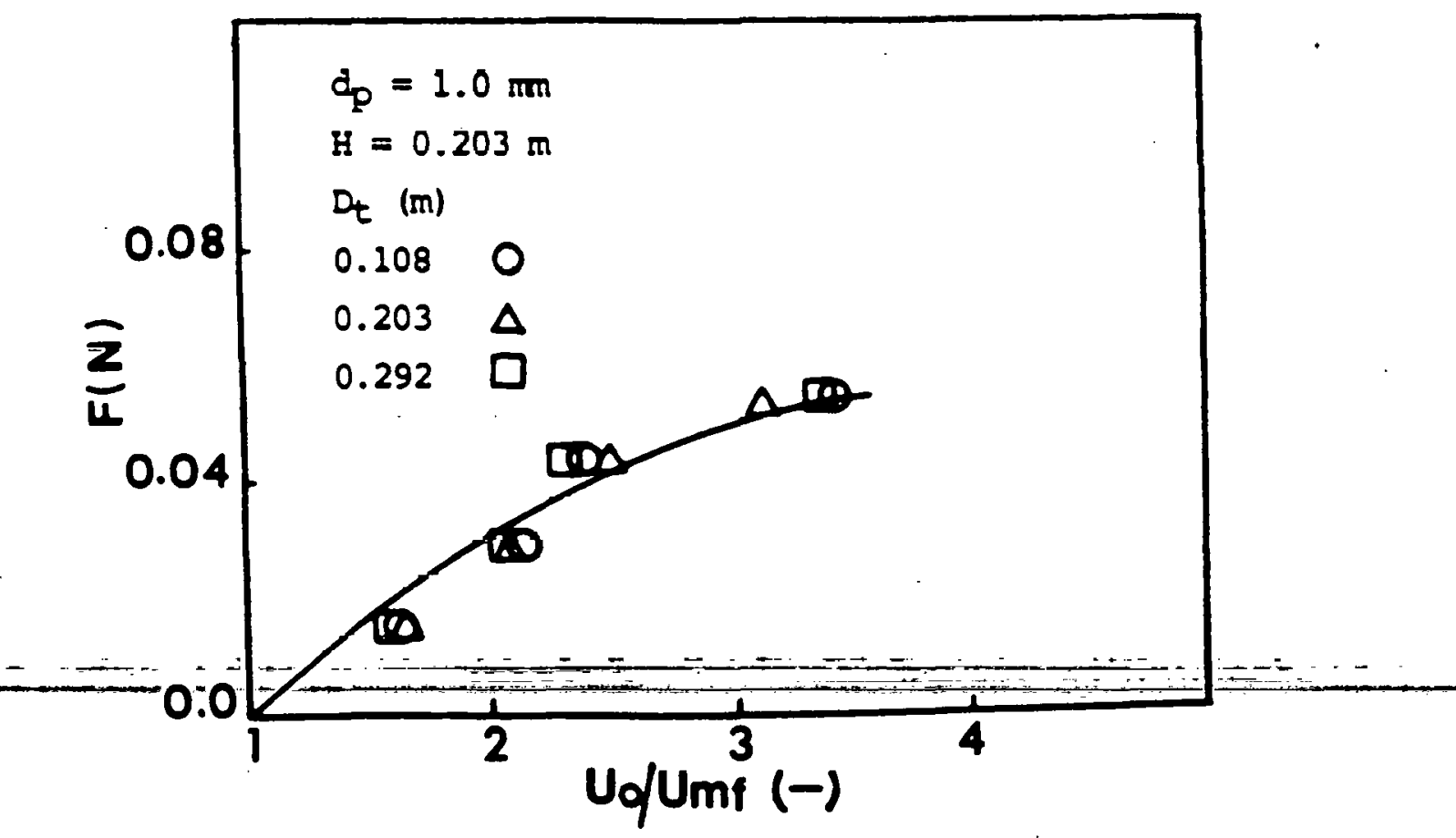

Figure 16. The Effect of Bed Dinmeter on the Prevalling Kinelic Forces in Fluidized Beds at a Bed Height of $0.203 \mathrm{~m}$ 


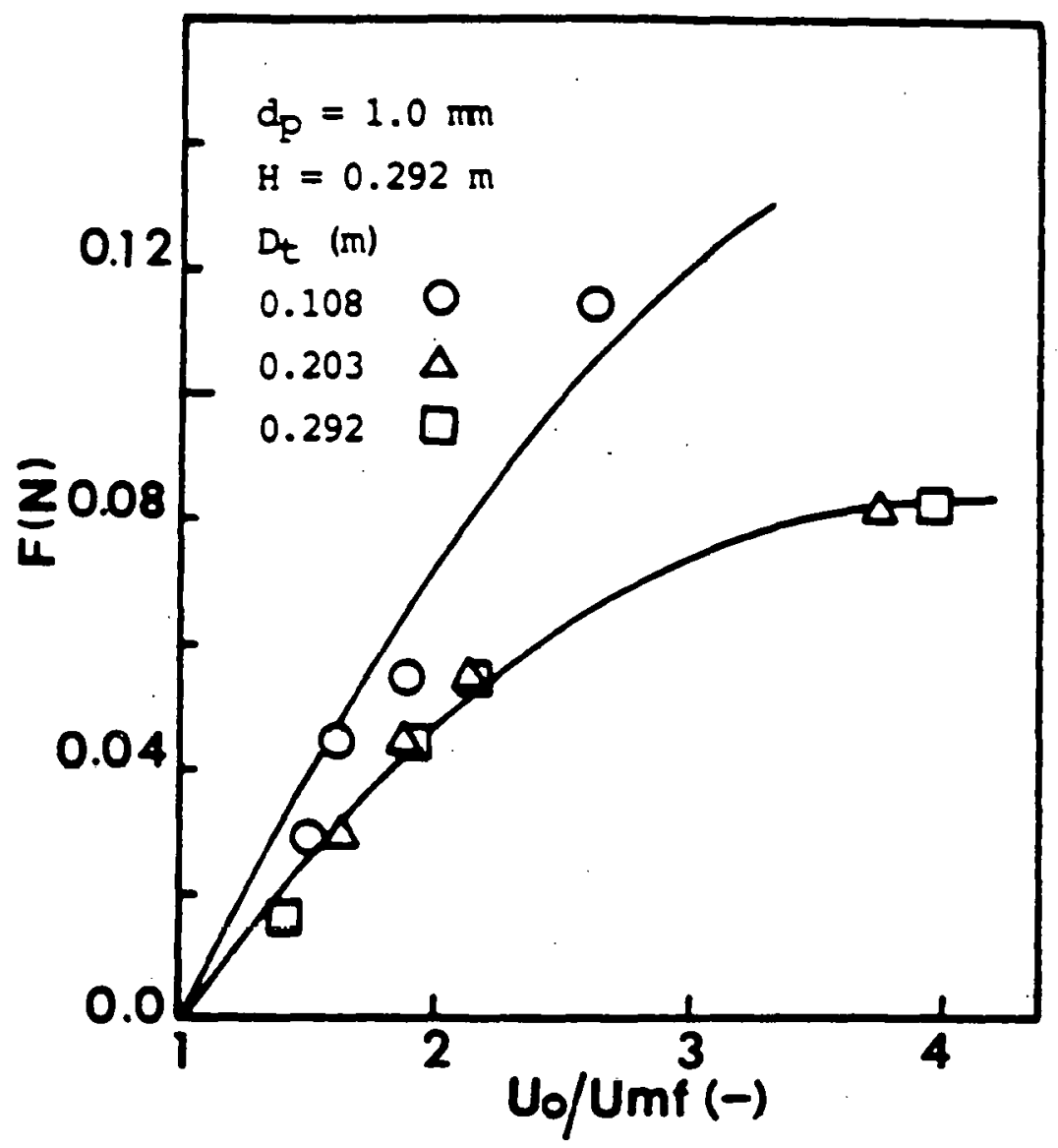

Figure 17. The Effect of Bed Diameter on the Prevailing Kinetic Forces in Fluidized Beds at a Bed Height of $0.29 \% \mathrm{~m}$ 


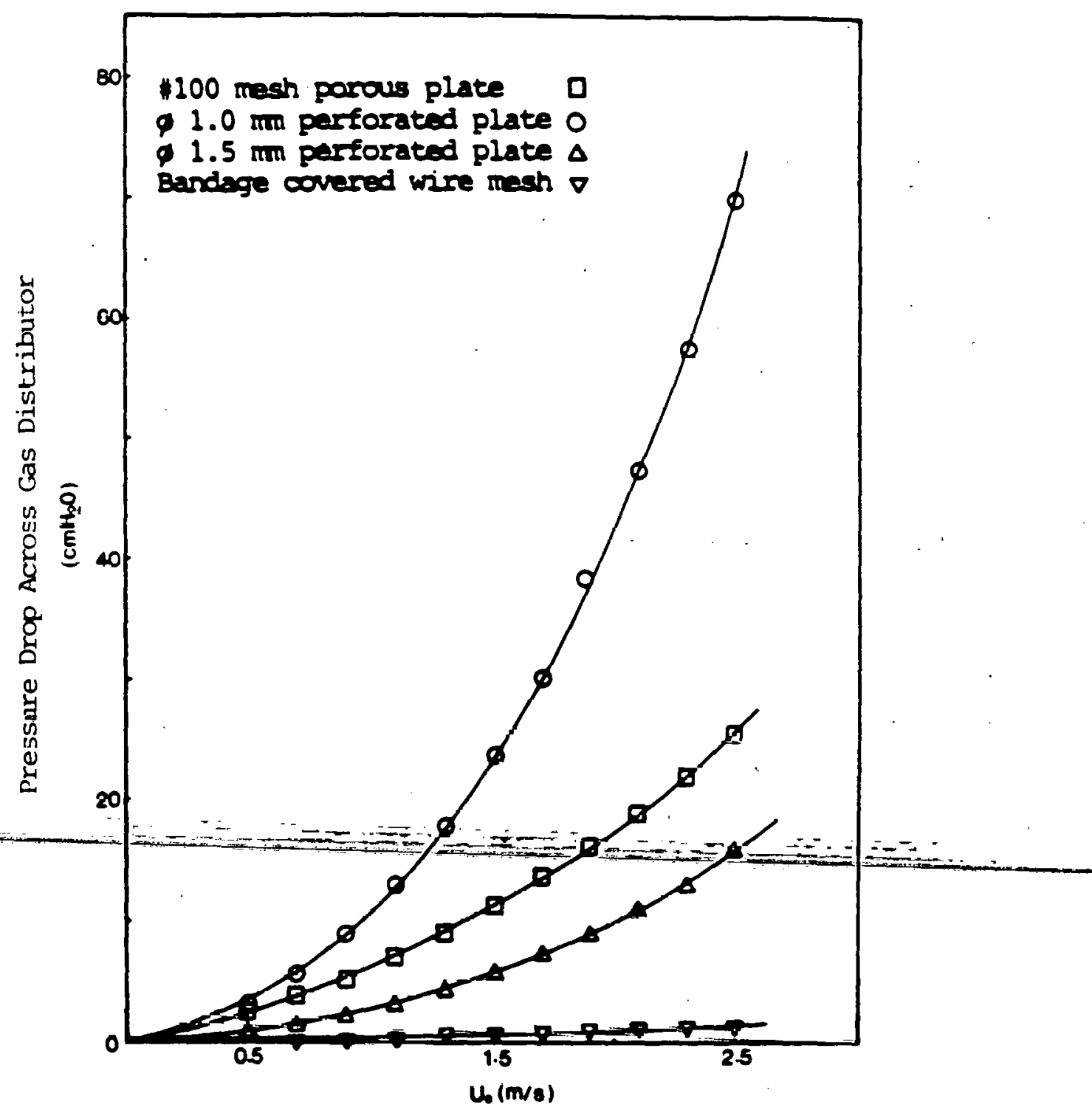

Figure 18. The Relationship Between the Pressure Drop Across Gas Distributors and Superficial Gas Velocity 


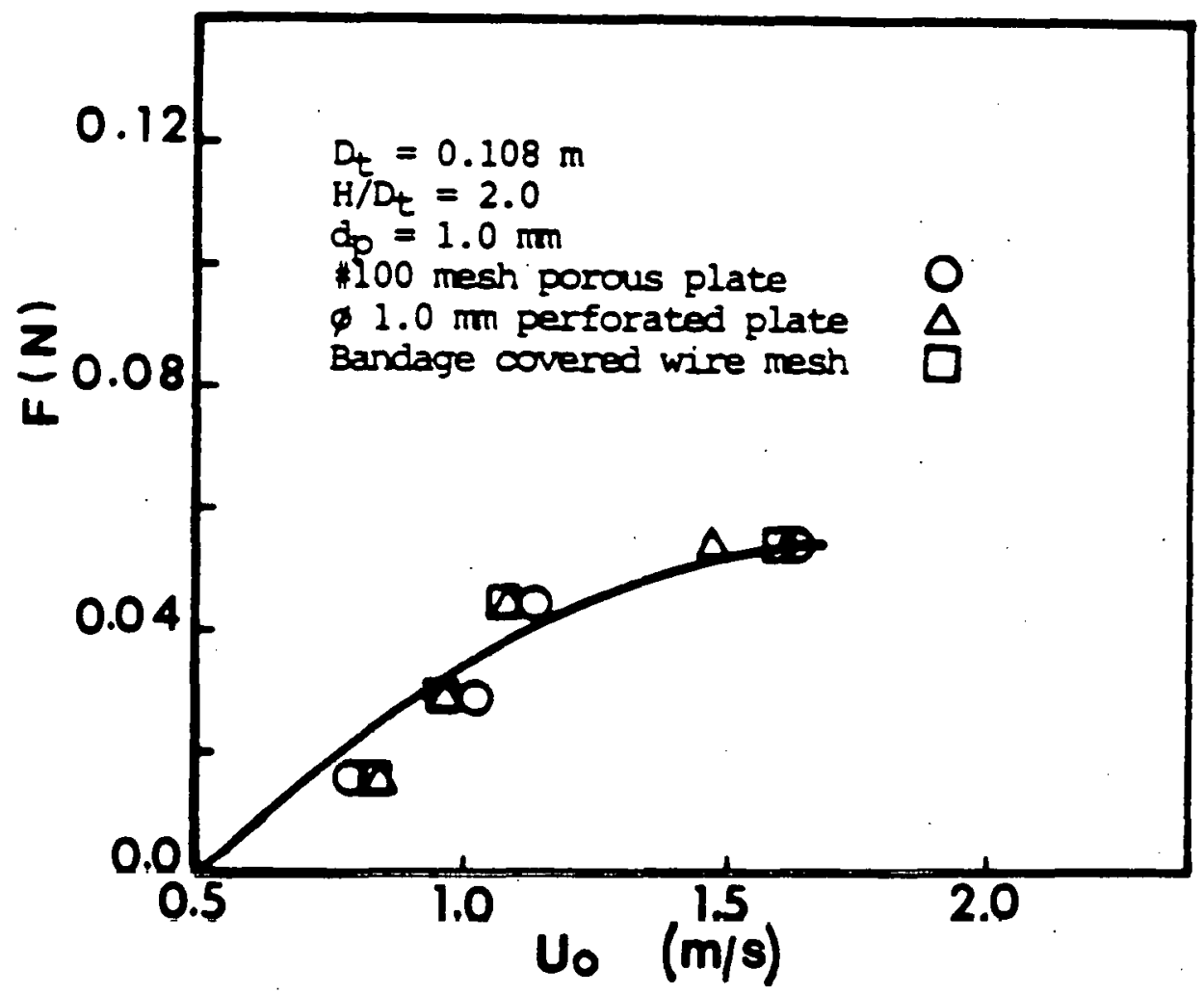

Figure 19. The Effect of the Gas Distributor on Prevailing Kinetic Forces in a Fluidized Bed at Low Gas Velocities 


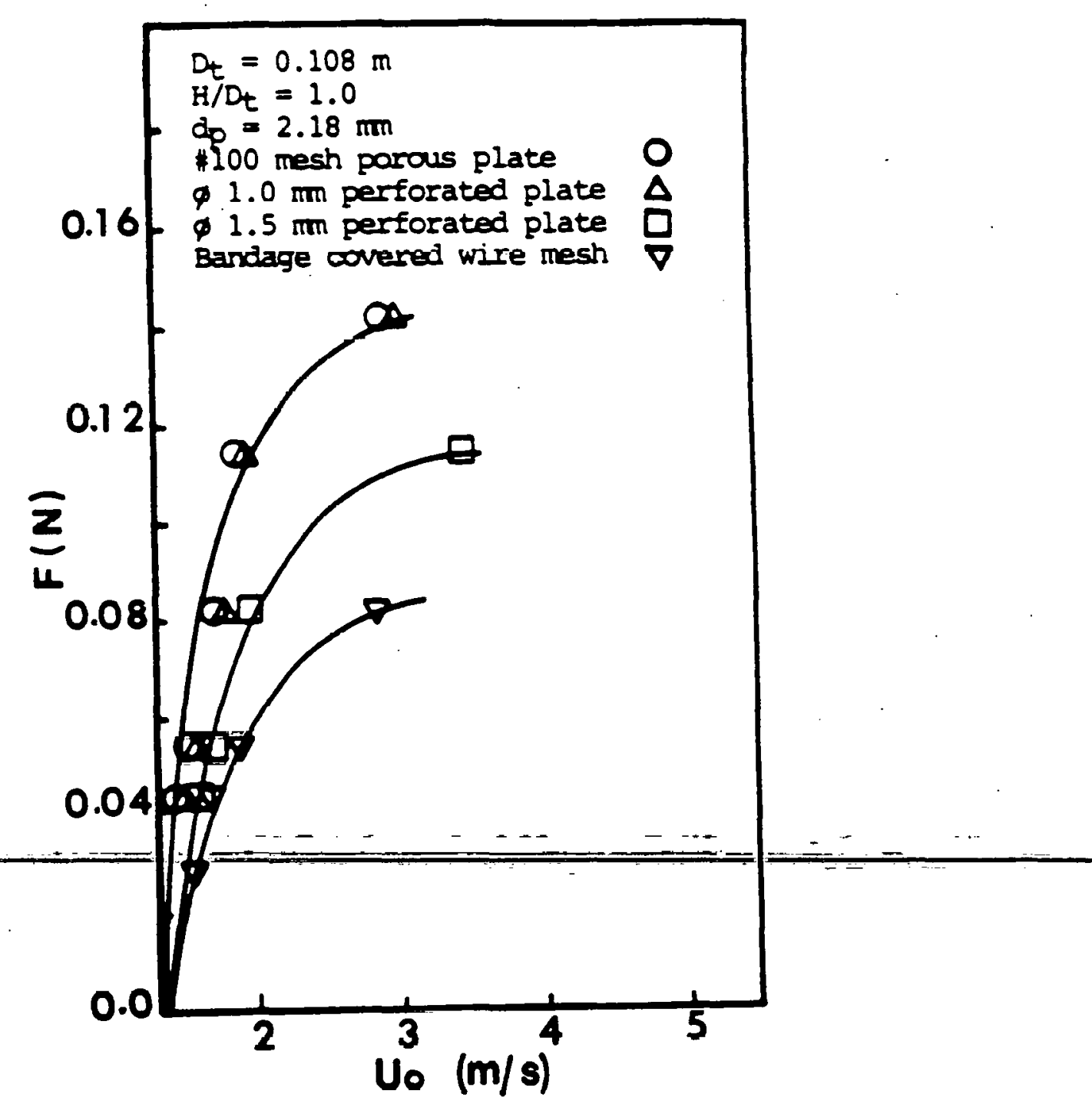

Figure 20. The Effect of the Gas Distributor on Prevalling Kinetic Forces in a Fluidized Bod at High Gns Velocitios 


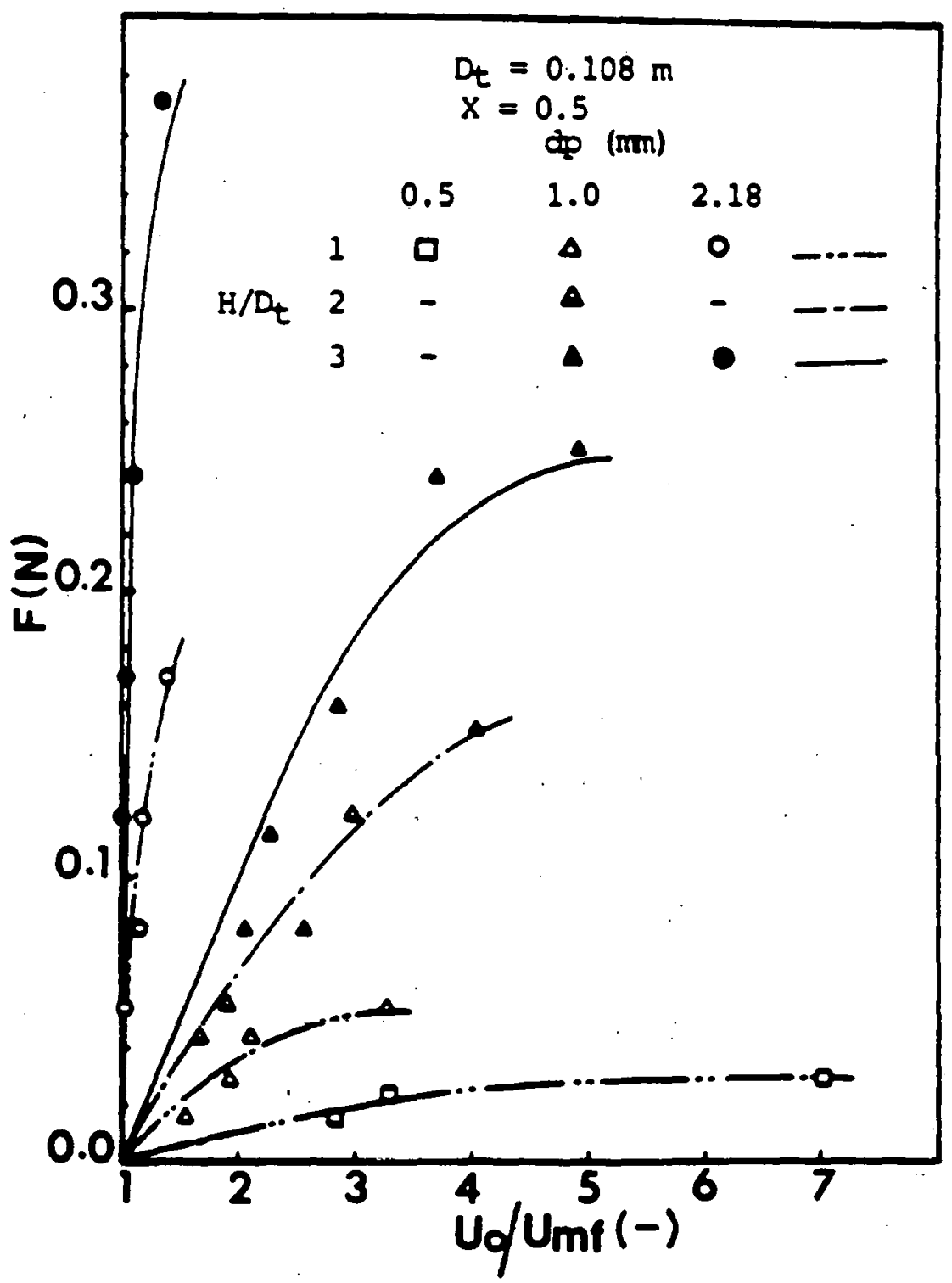

Figure 21. The Effects of Particle Size, Gas Velocity and Bed Height on the Prevailing Kinetic Forces in a $0.108 \mathrm{~m}$ I.D. Spouted Fluidized Bed at $\mathrm{X}=0.5$ 
the kinetic forces of solid particles in a spouted fluidized bed as in a circular fluidized bed. However, the effect of the volumetric flow ratio of fluidizing air through the jet opening had a complicated effect on the kinetic forces of fluidized particles. As seen in Figure 22, the kinetic forces of solid particles in a spouted bed $(X=1.0)$ are relatively greater than those in a spouted fluidized bed. Also, the kinetic forces of solid particles in the spouted fluidized bed at $X=0.5$ are greater than those at $X=0.3$ and 0.7 . This reveals that both the jet and the conical perforated gas distributor are responsible for developing the kinetic forces of solid particles in a spouted fluidized bed. This observation is consistent with the experimental results, which show that the kinetic forces of solid particles in both the spouted bed $(X=1.0)$ and the circular bed with a conical perforated gas distributor $(X=0.0)$ are greater than those in regular circular fluidized beds.

The kinetic forces of fluidized particles in a square fluidized bed were measured. (See Figure 23.) The general tendency io oimilar to that observed in the circular fluidized beds. The kinetic forces prevailing in a two-dimensional bod were also measuren. The bed configuration was proven to have an influence on the kinetic forces of fluidized particles. The results are shown in Figure 24. As mentioned earlier, the presence of large bubbles and unstable fluidization indicates sluggiug. The degree of olugging in a fluidizen bed depends on how the gas bubbles grow in the bed. At the same ouperficial gas velocity and bed height, experiments showed that a circular bed tends to have more slugging and higher kinetic forces than a square fluidized bed. The degree of slugging in a two-dimensional fluidized bed is lower than that in a square fluidized bed, and the kinetic forces in a twodimensional fluidized bed are lower than those in a square fluidized bed. The influence of bed configuration on kinetic forces may be because of the wall effect; however, more investigation is necessary to reach a final conclusion. The spouted fluidized bed has higher kinetic forces than a circular fluidized bed of the same size because of the existence- of an $=$ air $=$ jet. 


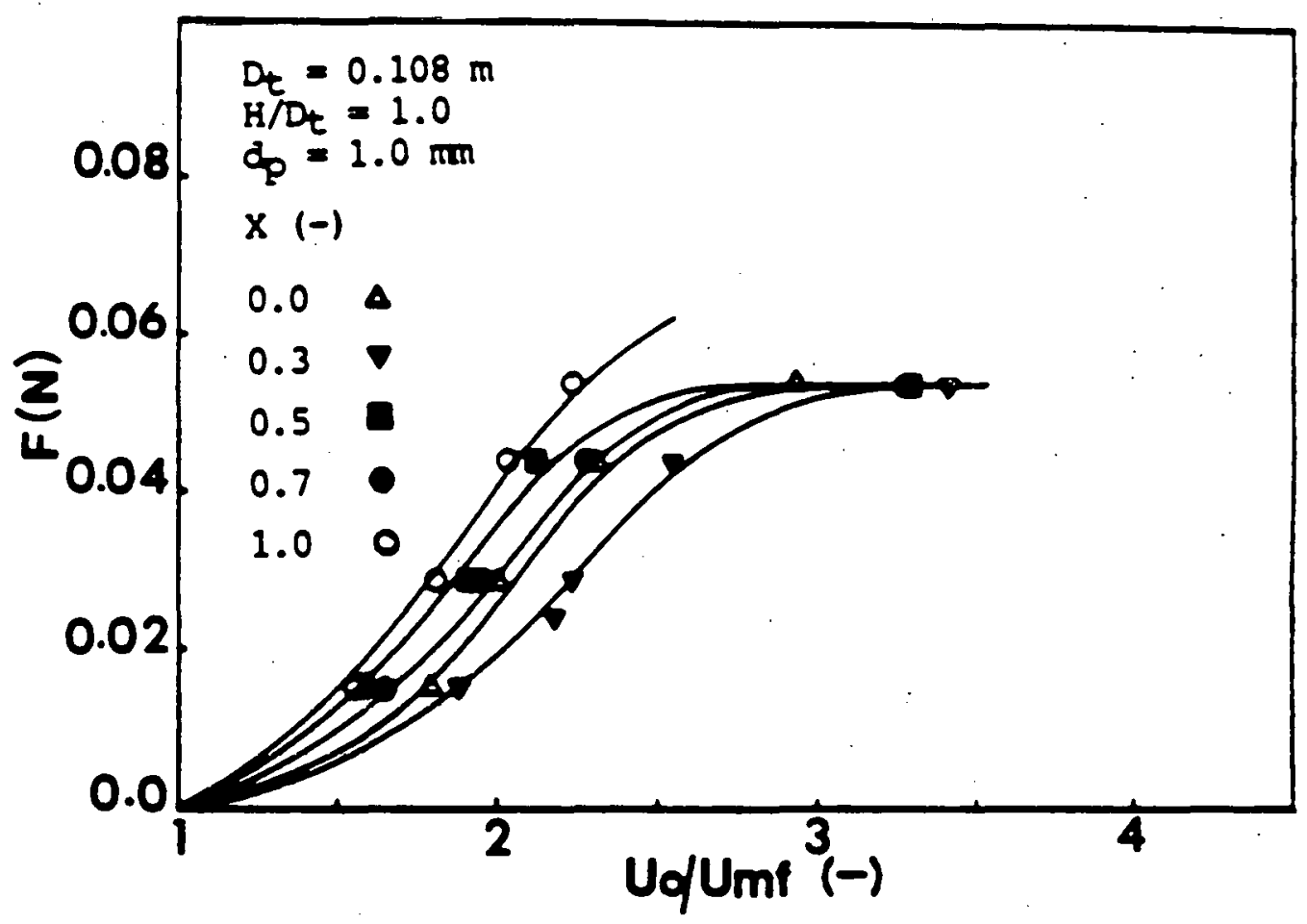

Figure 22. The Bffect of Volumetric Flow Ratio on the Prevailing Kinetic Forces in a $0.108 \mathrm{~m}$ I.D. Spouted Fluidized Bed 


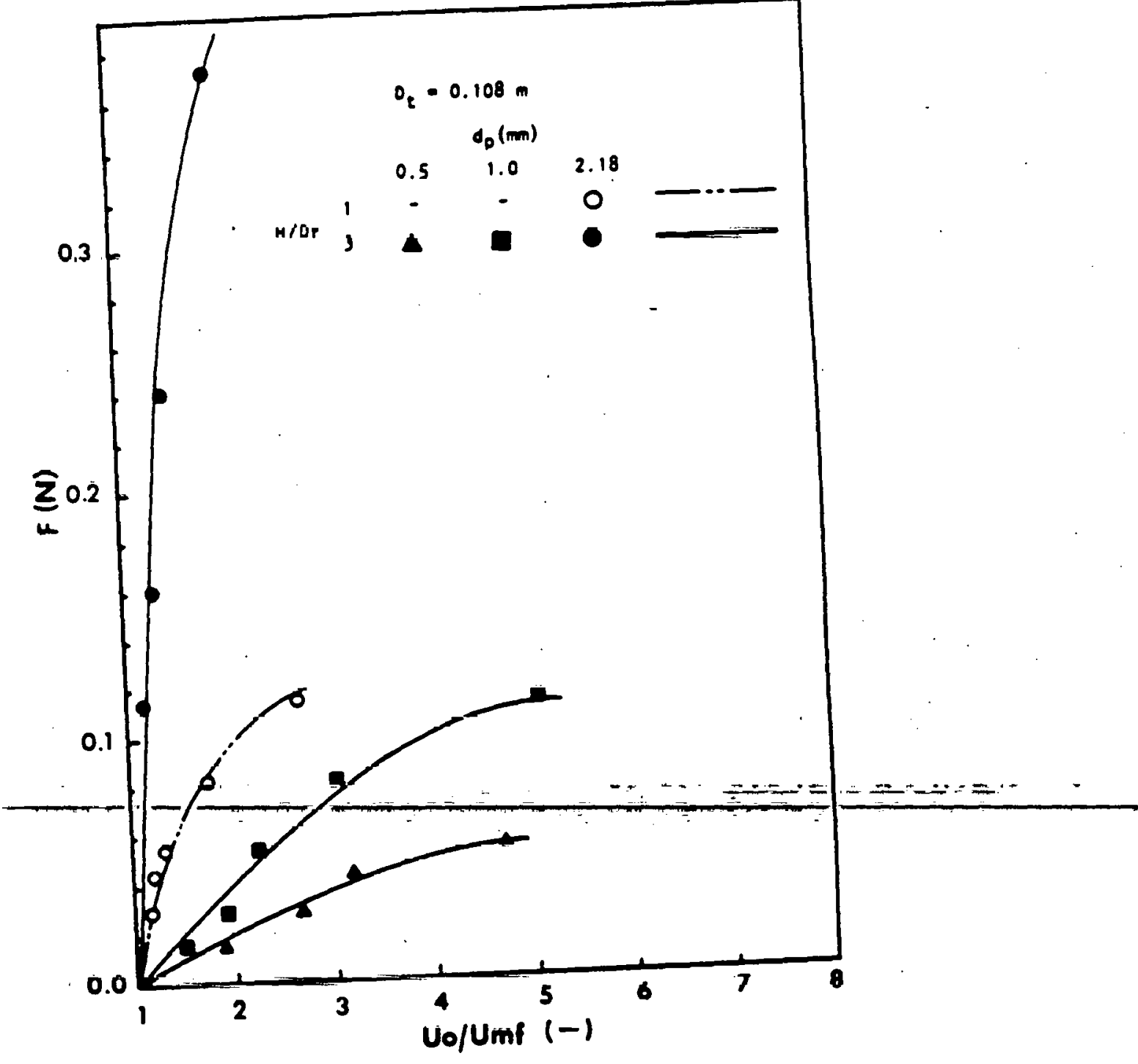

Figure 23. Kinetic Forces of Solid Particles in a $0.108 \mathrm{~m}$ Square Fluidized Bed 


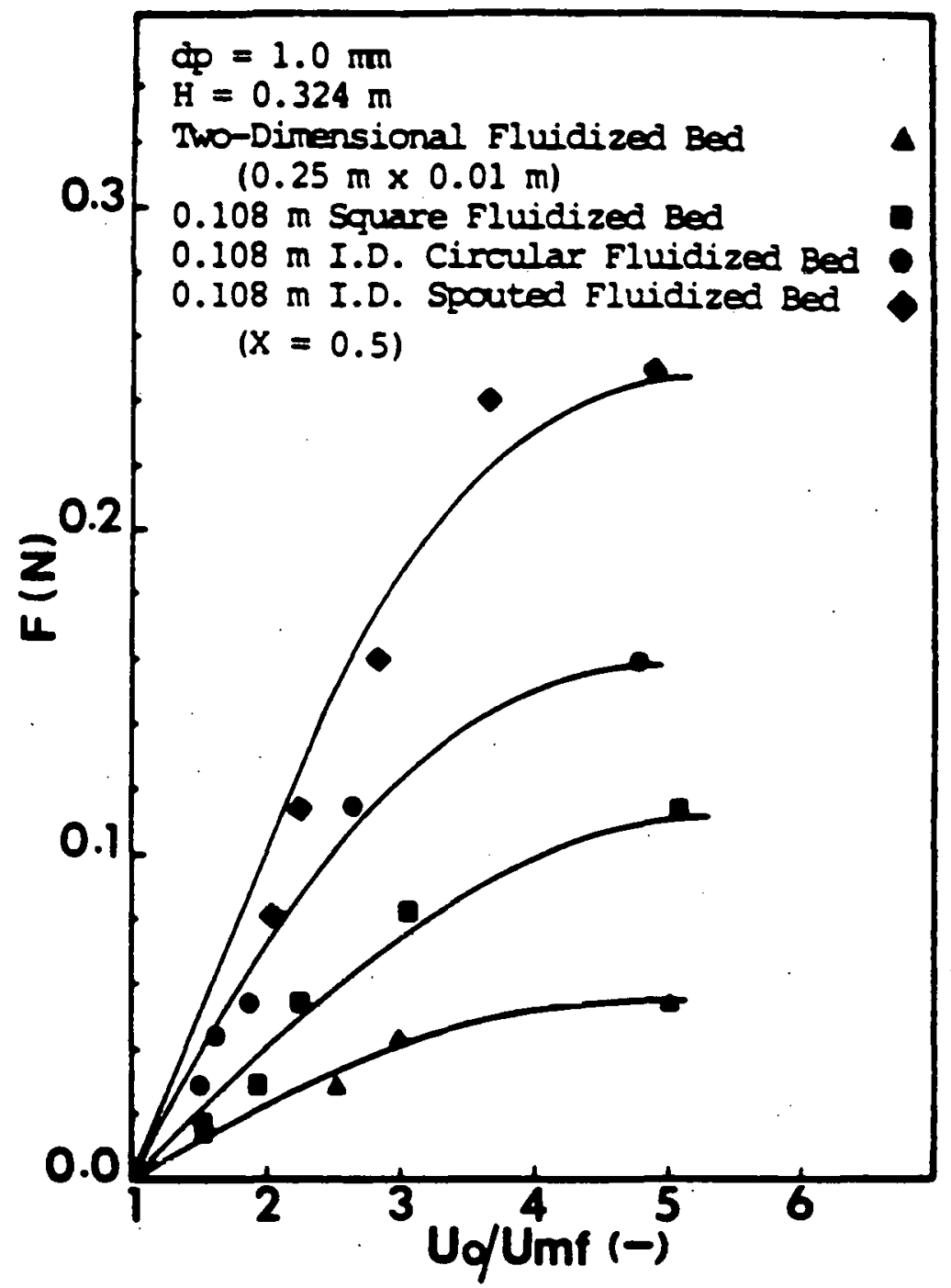

Figure 24. Comparison of Kinetic Forces of Solid Particles in Various Fluidized Beds 


\subsection{CONCLUSION}

The maximum force of solid particles in fluidized beds has been measured using the fracture-sensitive tracer-particle method. To investigate the stochastic behavior and force distribution of solid particles, the piezoresistive strain-gauge method and the pressure fluctuation method should also be employed. Based on a comprehensive understanding of the kinetic behavior of fluidized particles, combined with erosion and attrition experiments in fluidized beds, a model will be developed to assist in designing and operating fluidized-bed combustors and gasifiers. This project will focus on these tasks during the next 2 years. 


\subsection{NOMENCLATURE}

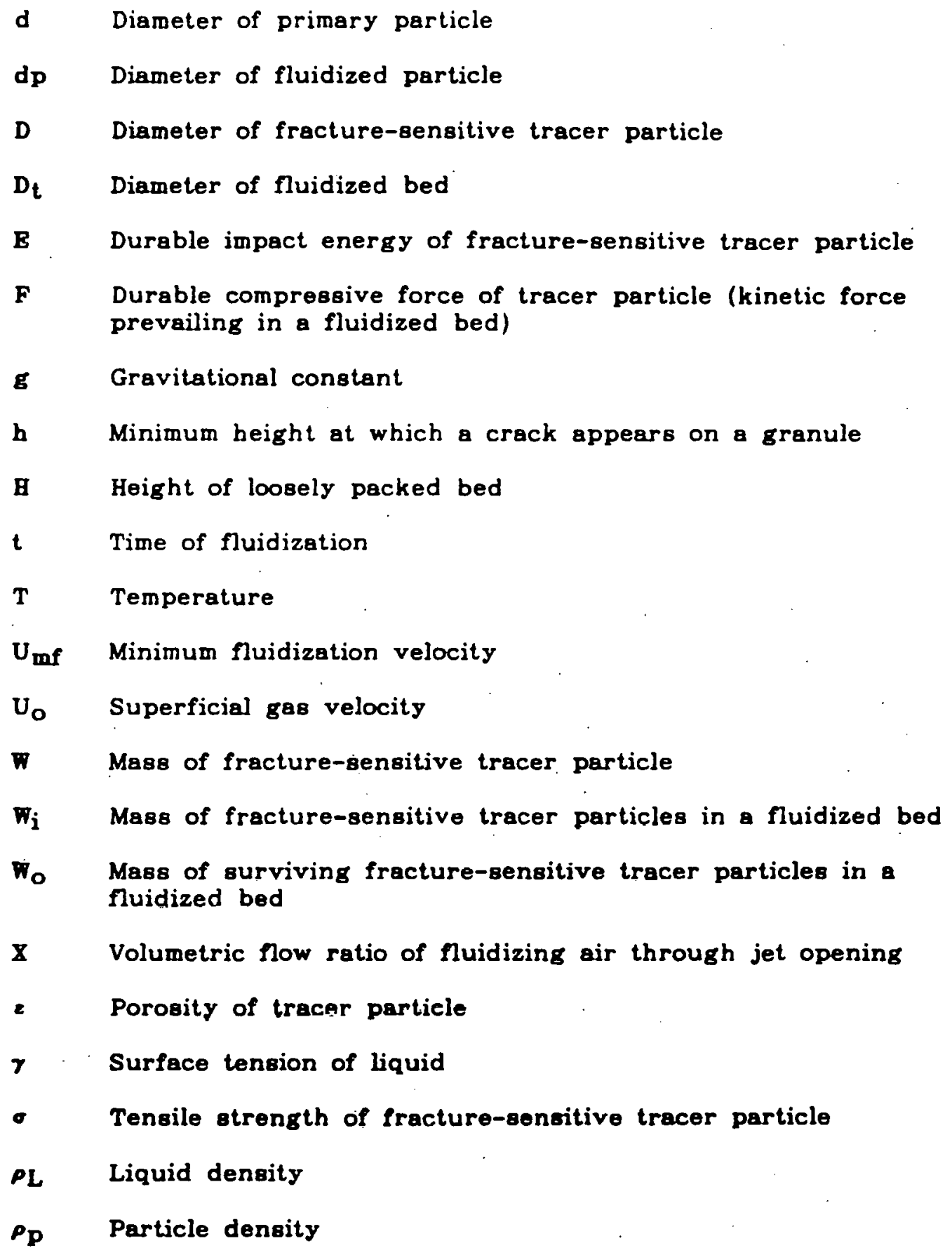




\subsection{REFERENCES}

Hartley, D.A., and Parfitt, G.D. 1984. An Improved Split-Cell Apparatus for the Measurement of Tensile Strength of Powders. Journal of Physics E: Scientific Instruments 17:347.

Heertjes, P.M., Verloop, J., and Willems, R. 1970. The Measurement of Local Mass Flow Rates and Particle Velocities in Fluid-Solid Flow. Powder Technology 4:38.

Hiramatsu, Y., et al. 1965. Journal of Mining and Metal Ingtitute Japan $81: 1024$.

Kono, H.O. 1981. Attrition Rates of Relatively Coarge Particles in Various Types of Fluidized Beds. AIChE Symposium Series 77(205):96.

Kono, H.O., Soltani-Ahmadi, A., and Suzuki, M. 1987. Kinetic Forces of Solid Particles in Coarse Particles Fluidized Beds. Powder Technology 52:49.

Lin, J.S., Chen, M.M., and Chao, B.T. 1985. ^ Novel Kadioactive Particle Tracking Facility for Measurement of Solids Motion in Gas Fluidized Beds. AIChE Journal 31(3):466.

Marsheck, R.M., and Gomezplata, A. 1965. Marticle Flow Patterns in a Fluidized Bed. AIChE Journal 11(1):167.

Nguyen, T.H., and Grace, J.R. 1978. Forces on Objects Immersed in Fluidized Beds. Powder Technology 19:255.

Oki, K., Walawender, W.P., and Fan, L.T. 1977. The Measurement of Lucal Velocity of Solid Particles. powder Technology 18:171.

Rumpf, H. 1958. Grundlagen und Methoden des Granulierens. ChemieIngenieur-Technik 30:144,329.

Rasu, G.; and Tirghas8o, G. 1983. An Impact Probe for Local Analysis of Gas-Solid Flow8. Powder Technology 34:151.

Vaux, W.G., and Fellers, A.W. 1981. Measurement of Attrition Tendency in Fluidization. AIChE Symposium Series 77(205):10'. 
